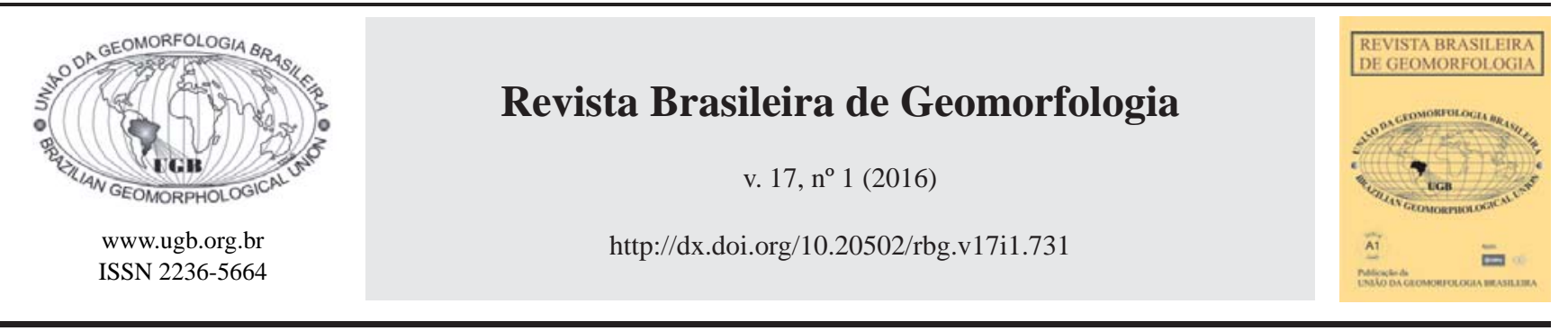

\title{
MAPEAMENTO GEOMORFOLÓGICO DA BACIA HIDROGRÁFICA DO RIO SÃO JOÃO (RJ) POR ANÁLISE DE IMAGENS ORIENTADAA OBJETO E MINERAÇÃO DE DADOS
}

\section{GEOMORPHOLOGICAL MAPPING OF SÃO JOÃO RIVER BASIN (RJ) THROUGH OBJECT BASED IMAGE ANALYSIS AND DATA MINING}

\author{
Raphael e Silva Girão \\ Departamento de Geologia, Universidade Federal do Rio de Janeiro \\ Av. Athos da Silveira Ramos, 274, Rio de Janeiro, Rio de Janeiro, CEP: 21941-916, Brasil \\ Email: raphaelgirao@hotmail.com \\ Claudio Limeira Mello \\ Departamento de Geologia, Universidade Federal do Rio de Janeiro \\ Av. Athos da Silveira Ramos, 274, Rio de Janeiro, Rio de Janeiro, CEP: 21941-916, Brasil \\ Email: limeira@geologia.ufrj.br
}

Pedro José Farias Fernandes

Laboratório de Geografia Física - Departamento de Geografia, Universidade Federal Fluminense Av. Litorânea s/n - Campus da Praia Vermelha, Boa Viagem, Niterói, RJ, CEP: 24030-346, Brasil

Email:pjffernandes@yahoo.com.br

\section{Informações sobre o Artigo}

Recebido (Received):

14/04/2015

Aceito (Accepted):

$16 / 10 / 2015$

\section{Palavras-chave:}

Mapeamento Geomorfológico; Sensoriamento Remoto; Análise de Imagem Orientada a Objeto.

\section{Keywords:}

Geomorphological mapping; Remote Sensing; Object Based Image Analysis.

\section{Resumo}

O presente estudo tem como objetivo principal a realização de mapeamento geomorfológico da Bacia Hidrográfica do Rio São João (RJ), na escala 1:100.000, por meio de análise de imagem orientada a objeto (OBIA) e empregando técnicas de mineração de dados para a definição dos limiares de classificação do relevo, com base em modelo digital de elevação e suas variáveis geomorfométricas, além de dados referentes ao substrato geológico. A utilização da análise de imagem orientada a objeto e da mineração de dados no mapeamento geomorfológico permitiu a classificação do relevo em diversas classes e em diferentes níveis taxonômicos, de forma ágil e simplificada, ficando evidente que dois fatores influenciaram fortemente os resultados: (i) a segmentação multirresolução associada à possibilidade de se manipular a contribuição de cada variável, pois permitiu a elaboração de estratégias de segmentação mais adequadas aos dados utilizados e às classes geomorfológicas mapeadas; e (ii) a seleção do conjunto amostral, pois tal tarefa possui uma relação direta na capacidade do minerador de dados definir parâmetros mais eficazes para a classificação do relevo. Vale ressaltar que a classificação geomorfológica por meio da análise de imagem orientada a objeto se destaca dos métodos convencionais devido a sua capacidade de classificação em diferentes níveis e sua rede hierárquica semântica, onde cada classe pode ser dividida em subclasses, adequando-se bem ao mapeamento 
geomorfológico taxonômico proposto. Por fim, destaca-se que, apesar do grande avanço no mapeamento por meio da OBIA e da mineração de dados, o conhecimento do intérprete sobre o conteúdo a ser mapeado continua a ser imprescindível para os procedimentos de classificação adotados.

\begin{abstract}
This article aims to generate a geomorphological map of the São João River Basin (RJ), on scale 1:100.000, using Object based image analysis (OBIA) and data mining techniques for classification based on digital elevation models, geomorphometric variables and geological substrate data. The use of OBIA and data mining for geomorphological mapping allowed a fast and simplified classification of relief in different classes and taxonomic levels. It was clear that two factors strongly influenced the results: (i) the multiresolution segmentation associated with the ability to manipulate the contribution of each variable, which allowed the development of the most appropriate strategy for classification; and (ii) the selection of training samples, as this task has a direct relation with data mining effectiveness for relief classification. The OBIA geomorphological classification stands out from conventional methods due to its ability for classification in different levels and due the hierarchical semantic network, where each class can be divided into subclasses, adapting well to proposed taxonomic geomorphological levels. Despite the great advances in the OBIA and data mining for classification, the knowledge of the interpreter about the content to be mapped continues to be critical in classification procedures adopted.
\end{abstract}

\section{Introdução}

O mapeamento geomorfológico constitui-se na representação da superfície terrestre com base em critérios específicos relacionados com o relevo, tais como morfologia, estrutura, gênese e cronologia (BISHOP et al., 2012), sendo útil para o entendimento dos processos atuantes na superfície terrestre e da evolução da paisagem, assim como para o levantamento de recursos minerais e identificação de riscos naturais.

Em função da necessidade de se representar uma grande quantidade de parâmetros e feições, a cartografia geomorfológica é uma atividade complexa, ainda mais devido ao fato de não existir uma padronização internacional de identificação e classificação de feições geomorfológicas. Desse modo, o que se faz na prática do mapeamento geomorfológico é escolher um conjunto de convenções adequadas à relação entre a aplicação desejada, o método adotado e a escala de representação, de maneira que os documentos cartográficos resultantes desempenhem sua função básica de informar de modo claro, legível e objetivo o tema em questão (CORREIA, 2008).

Nos últimos anos, os recursos da cartografia digital e dos Sistemas de Informações Geográficas (SIG) possibilitaram a criação de numerosa gama de mapas politemáticos, em função da combinação de diversos atributos e bases informacionais. No campo do sensoriamento remoto, desde as suas origens, fotografias aéreas têm sido amplamente utilizadas em procedimentos da cartografia geomorfológica, contudo, recentemente, novos produtos de sensoriamento remoto surgiram oriundos de uma ampla gama de sensores aerotransportados e orbitais, destacando-se também os métodos fotogramétricos, radargramétricos, interferométricos e de varreduras a laser que possibilitam a extração de modelos digitais de elevação (MDE) importantes nas análises geomorfológicas (CAMARGO et al., 2009).

Dessa maneira, o mapeamento geomorfológico tem presenciando avanços com a utilização de metodologias automáticas ou semiautomáticas de classificação de relevo, principalmente a partir de MDE, tornando assim tal tarefa mais rápida e eficaz (FERNANDES, 2013). Esse processo é ainda mais intensificado pelo aumento continuo da disponibilidade de bases de dados geomorfométricos (DRAGUT; BLASCHKE, 2006).

Nesse contexto, está inserida a análise de imagem orientada a objeto (OBIA - object based image analysis), que não tem como foco as análises baseadas nos pixels das imagens, mas tem como unidades de processamento básico os objetos gerados pelos algoritmos de segmentação (BENZ et al., 2004; BAATZ; SCHÄPE, 2000). De acordo com Navulur (2007), em imagens de sensoriamento remoto, um objeto pode ser definido como um agrupamento de pixels com propriedades espectral e espacial homogêneas. Um objeto possui, além de valores espectrais, diversos outros atributos, incluindo forma, textura, morfologia, contexto e outros, que podem ser utilizados em análise de imagens.

Além disso, há a possibilidade de se gerar diferen- 
tes níveis de segmentação na abordagem multirresolução e, assim sendo, cada objeto identifica seus objetos vizinhos, os superobjetos e os subobjetos, possibilitando o respeito das bordas de cada um deles nas análises. A partir, principalmente, de tais características, é permitida a estruturação espacial e semântica do conteúdo de uma imagem pela inserção do conhecimento especialista em uma rede hierárquica (BENZ et al., 2004). Essa característica é uma das vantagens da OBIA no mapeamento geomorfológico, pois permite a classificação do relevo em diferentes níveis, adequando-se bem ao mapeamento geomorfológico taxonômico (DRAGUT; BLASCHKE, 2006).

Recentemente, uma série de trabalhos de mapeamento geomorfológico foram desenvolvidos a partir da utilização de OBIA: Dragut e Blaschke (2006), Asselen e Seijmonsbergen (2006), Anders et al. (2011), Verhagen e Dragut (2012), e, Dragut e Eisank (2012). No Brasil, há trabalhos como os de Camargo et al. (2009), que utilizaram OBIA para o mapeamento geomorfológico do município de São José dos Campos, utilizando um MDE oriundo do sensor ASTER; e de Fernandes (2013), que utilizou OBIA e MDE oriundos do SRTM para o refinamento de um mapa geomorfológico do projeto RADAMBRASIL. Nesses trabalhos, tal abordagem tem apresentado potencial para o mapeamento geomorfológico, permitindo mapear as feições do relevo de forma simples e rápida. Contudo, na maior parte dos estudos desenvolvidos, optou-se por utilizar somente dados de entrada quantitativos para o mapeamento, principalmente MDE e suas variáveis, ignorando informações qualitativas importantes para a cartografia geomorfológica, como dados referentes à geologia.

Outra técnica importante que pode ser associada a OBIA na classificação de imagens é a mineração de dados, que, segundo Witten et al. (2011), consiste no processo automático ou semiautomático de identificação de padrões nos dados. A mineração de dados permite a identificação dos atributos mais adequados e eficientes para distinguir classes diferentes, baseada em um conjunto amostral de objetos referentes a cada uma dessas classes.

Sendo assim, o presente estudo adota o método da análise de imagem orientada a objeto (OBIA) com o objetivo de realizar um mapeamento geomorfológico da Bacia Hidrográfica do rio São João (RJ), na escala 1:100.000, definindo os parâmetros de classificação do relevo por meio de mineração de dados, com base em modelo digital de elevação (MDE) e suas variáveis geomorfométricas (VG), além de dados referentes ao substrato geológico. Considera-se que o método adotado favoreça o desenvolvimento de um mapeamento geomorfológico de forma ágil, com uma gama de informações mais complexa para a diferenciação do relevo e estabelecendo limiares bem definidos para o estabelecimento de cada classe geomorfológica.

\section{2. Área de Estudo}

A Bacia Hidrográfica do Rio São João (BHSJ) - Figura 1 - localiza-se na Região das Baixadas Litorâneas do estado do Rio de Janeiro, estendendo-se pelos municípios de Cachoeiras de Macacu, Rio Bonito, Araruama, Silva Jardim, Casimiro de Abreu, São Pedro da Aldeia, Rio das Ostras e Cabo Frio, ocupando uma área de aproximadamente $2.100 \mathrm{~km}^{2}$.

Geologicamente, o estado do Rio de Janeiro está situado na Província Mantiqueira, mais precisamente na Faixa Ribeira, resultado de orogêneses do Ciclo Brasiliano (Neoproterozoico-Eopaleozoico), caracterizado por metamorfismo, fusão parcial das rochas, deformações, cisalhamento transcorrente regional e granitogênese (SILVA; CUNHA, 2001). As rochas mais antigas da área de estudo datam do Paleoproterozoico, como os gnaisses do Complexo Região dos Lagos, localizados na porção do médio e baixo curso da BHSJ. A maior parte das rochas da área de estudo data do Mesoproterozoico-Neoproterozoico (complexos Paraíba do Sul e Búzios) e do Neoproterozoico (Complexo Rio Negro e Suíte Desengano), esses últimos resultado da granitogênese que ocorreu na sequência das orogêneses do Ciclo Brasiliano. No Cambriano, um magmatismo tardio a pós-tectônico em relação aos orógenos do Brasiliano resultou em granitogênese que originou os Granitoides Pós-Tectônicos, encontrados no alto e médio curso da BHSJ. Durante o Mesozoico-Cenozoico, nova fase de magmatismo, relacionado à Reativação Sul-Atlantiana, deu origem a plútons alcalinos, representados na área de estudo pelo Morro de São João. Atividades tectônicas cenozoicas levaram à reativação de falhas antigas e ao desenvolvimento de um sistema de riftes, onde se instalaram depósitos sedimentares paleogênicos, neogênicos e quaternários. A sedimentação quaternária na área de estudo ocorre associada a ambientes deposicionais continentais e transicionais/marinhos (SILVA; CUNHA, 2001) (Figura 2). 
Girão R. S. et al.

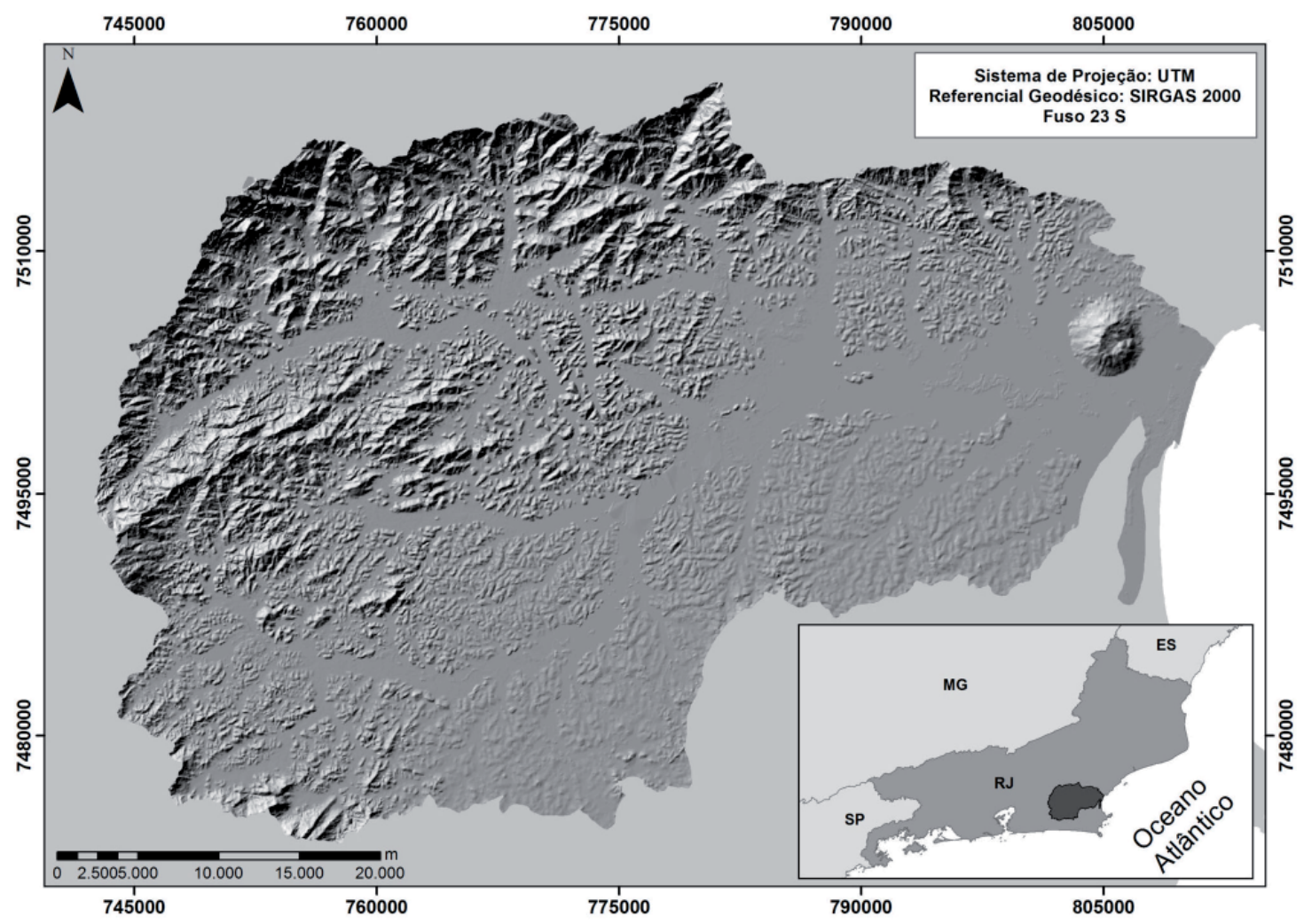

Figura 1 - Localização da Bacia Hidrográfica do rio São João (BHSJ) no estado do Rio de Janeiro e mapa de relevo sombreado da bacia, obtido por meio de MDE (IBGE).

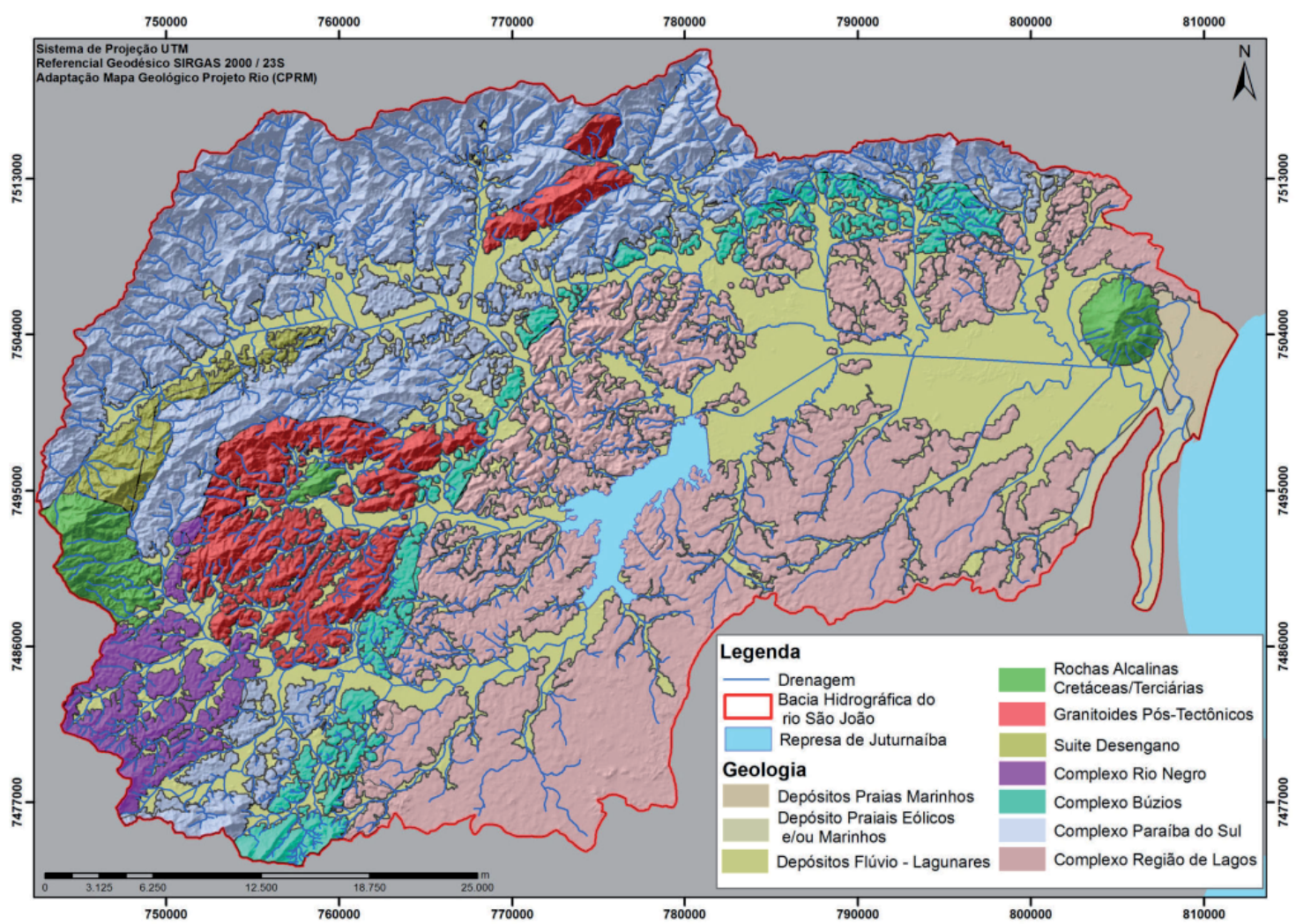

Figura 2 - Mapa de Unidades Geológicas da BHSJ (Modificado de Silva \& Cunha, 2001). 
A geomorfologia da BHSJ apresenta desde relevos proeminentes e escarpados até amplas planícies. De acordo com Dantas (2001), a área de estudo está inserida em dois domínios morfoestruturais (Cinturão Orogênico do Atlântico e Bacias Sedimentares Cenozoicas), abrangendo cinco domínios morfoesculturais (Maciços Costeiros e Interiores, Maciços Alcalinos Intrusivos, Superfícies
Aplainadas nas Baixadas Litorâneas, Escarpas Serranas, e Planícies Flúvio-Marinhas), e dez sistemas de relevo (Planície Aluvial, Planície Costeira, Planície Flúvio-Lagunar, Domínio Suave Colinoso, Domínio Colinoso, Alinhamentos Serranos e Degraus Estruturais, Maciços Intrusivos Alcalinos, Maciços Costeiros e Interiores, Escarpas Serranas, e Domínio Montanhoso) (Figura 3).

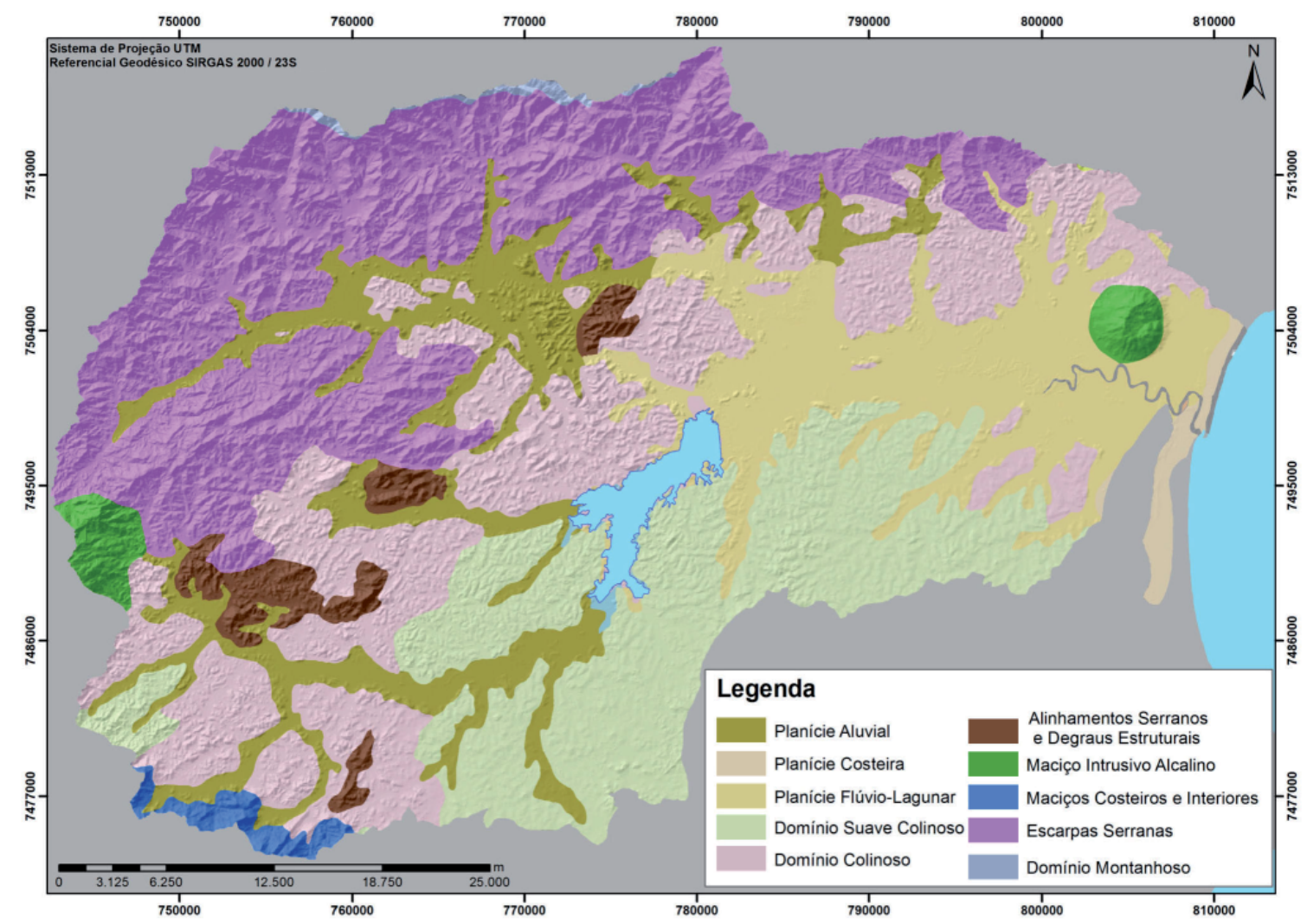

Figura 3 - Recorte da área de estudo do Mapa Geomorfológico do estado do Rio de Janeiro sobre relevo sombreado (modificado de DANTAS, 2001).

A BHSJ foi selecionada para o presente estudo devido a seu relevo heterogêneo e também pelo fato de apresentar tanto setores com predomínio de processos e feições continentais, como de predomínio de feições e processos costeiros, possuindo, assim, potencial para a avaliação da eficiência da metodologia adotada para o mapeamento geomorfológico proposto.

Utilizando distintas escalas e abordagens metodológicas, Dantas (2001), Silva (2002) e Seabra (2012) produziram mapas geomorfológicos da área de estudo. O primeiro se destaca pela utilização de diferentes informações para o mapeamento: dados geomorfométricos, morfogenéticos e acerca do substrato geológico. Contudo, a metodologia utilizada por Dantas (2001) se caracteriza pela alta demanda de tempo e relevante sub- jetividade na diferenciação das feições. Já Silva (2002) e Seabra (2012) se destacam por apresentarem uma metodologia com automatização dos procedimentos de mapeamento, entretanto ambos utilizam somente dados geomorfométricos, o que resulta em algumas simplificações ao representarem feições com gênese e geologia distintas em uma mesma classe geomorfológica.

\section{Materiais e Métodos}

\subsection{Materiais}

Para o presente estudo foram utilizados os seguintes materiais:

- Modelos digitais de elevação (MDE), na escala 
1:25.000, do Projeto RJ-25 do Instituto Brasileiro de Geografia e Estatística (IBGE) com resolução espacial de 20 metros;

- Fotografias aéreas ortorretificadas do ano de 2005, na escala 1:25.000, originadas do Projeto RJ-25 do Instituto Brasileiro de Geografia e Estatística (IBGE) com resolução espacial de 0,7 metros;

- Cartas topográficas na escala 1:50.000 do Instituto Brasileiro de Geografia e Estatística (IBGE), no formato vetorial;

- Mapa geológico do estado do Rio de Janeiro, na escala 1:400.000, elaborado pela Companhia de Pesquisa de Recursos Minerais (CPRM) em 2001 (SILVA; CUNHA, 2001).

\subsection{Preparação dos Planos de Informação (PI) e do Banco de Dados}

Os PI e o banco de dados foram compostos pelas variáveis geomorfométricas (VG), relevo sombreado, cartas topográficas do IBGE na escala 1:50.000, ortofotos do IBGE na escala 1:25.000 e Mapa de Unidades Geológicas na escala 1:100.000 (Figura 4).

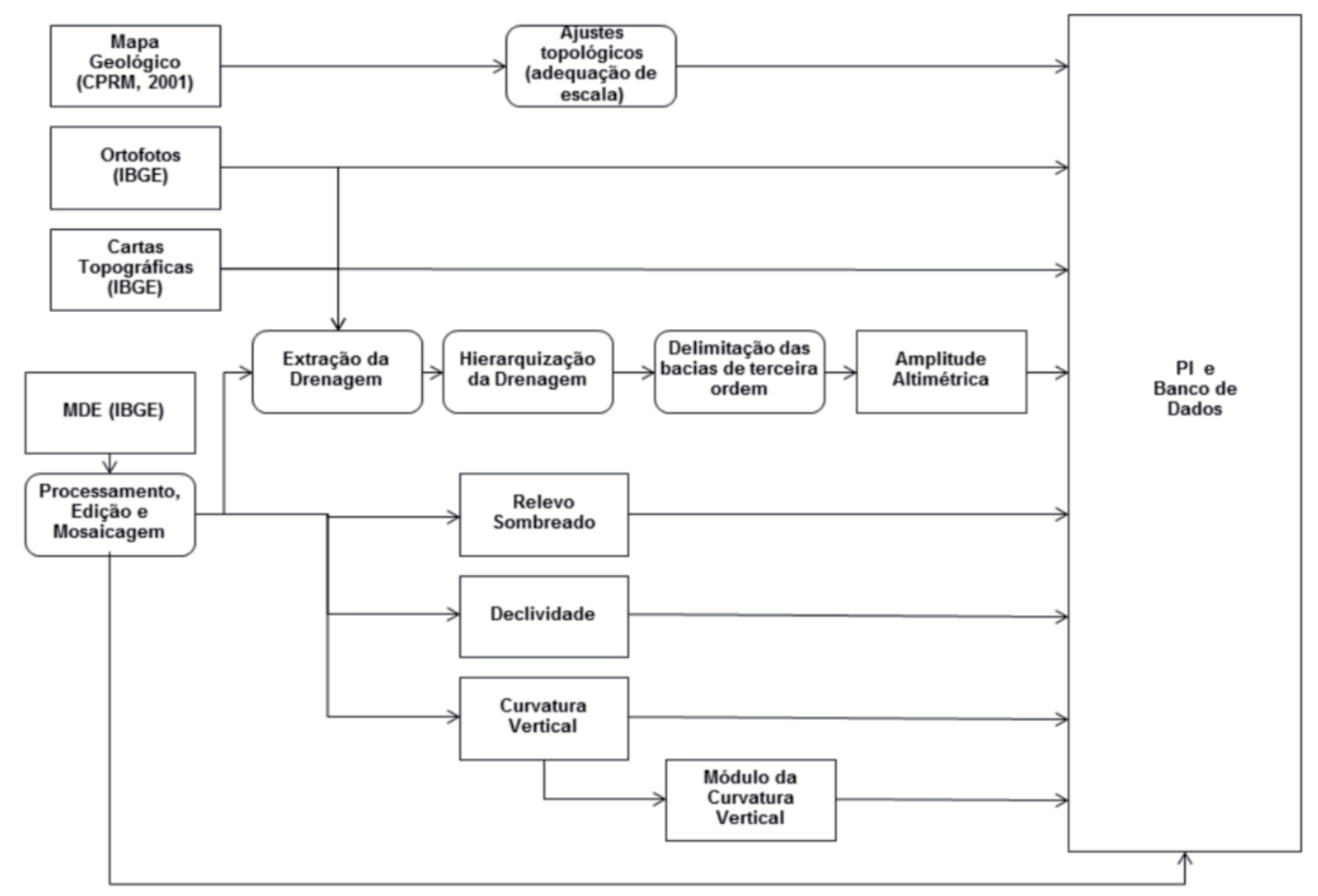

Figura 4 - Fluxograma das etapas de preparação do PI e do Banco de Dados.

Os MDE do IBGE foram gerados automaticamente por correlação de imagens utilizando o algoritmo $D L T$ - Direct Linear Transformation. Tal processo pode ocasionar anomalias nos modelos, principalmente nas áreas de maior rugosidade do terreno, devido às limitações práticas da correlação (por exemplo, áreas de sombra). Essas anomalias normalmente são caracterizadas por desníveis, tabuleiros de forma triangular e padrões de valores que não correspondem com o terreno. Sendo assim, foram executadas filtragens nos MDE visando atenuar tais anomalias para, então, proceder a mosai- cagem dos mesmos.

Posteriormente, em ambiente SIG foi possível obter rasters com informações sobre declividade, curvatura vertical e com o relevo sombreado da área de estudo. O primeiro é calculado com base na análise dos desníveis entre pixels vizinhos; o segundo é calculado a partir da comparação entre diferenciais altimétricos recíprocos ao ponto (pixel) sob análise, feita através de janelas móveis; e o terceiro é obtido por meio da criação de uma posição de uma fonte de luz hipotética, a partir da qual se calcula os valores de iluminação de cada pixel 
em relação às células vizinhas (VALERIANO, 2008).

Além disso, foi obtido também o raster do módulo da curvatura vertical da área de estudo. Para isso, o raster de curvatura vertical foi reclassificado, de modo que os pixels com valores negativos assumissem o valor de -1 (um negativo) e os pixels com valores positivos assumissem o valor de 1 (um). Posteriormente, através de uma álgebra de mapas, o raster reclassificado foi multiplicado pelo raster de curvatura vertical, resultando no raster do módulo da curvatura vertical.

A obtenção do raster com as informações de amplitude altimétrica consistiu em um processo mais complexo e dividido em quatro etapas: (i) extração de drenagem; (ii) hierarquização da drenagem; (iii) delimitação das sub-bacias de terceira ordem; e (iv) cálculo da amplitude altimétrica. Todas essas etapas foram executadas em ambiente SIG.
O processo de extração de drenagem consiste basicamente em três etapas: geração de um raster de direção do fluxo; geração de um raster de acumulação do fluxo; e extração da drenagem. A geração do raster de direção do fluxo é executada a partir da comparação entre valores dos pixels vizinhos do MDE, sendo que o fluxo segue para o pixel vizinho com menor valor altimétrico; dessa forma, os pixels do raster criado apresentam valores correspondentes à direção do fluxo. Então, com base no raster de direção de fluxo gerado, o sistema percorre cada pixel e calcula quantos pixels contribuem com fluxo para um determinado pixel, atribuindo para o mesmo este valor; sendo assim, o algoritmo gera um novo raster com o fluxo acumulado para cada pixel (Figura 5). Por fim, a partir de um valor de fluxo acumulado selecionado, foi possível extrair a drenagem da área de estudo. Tal drenagem foi verificada e refinada com o auxílio das cartas topográficas e das ortofotos.

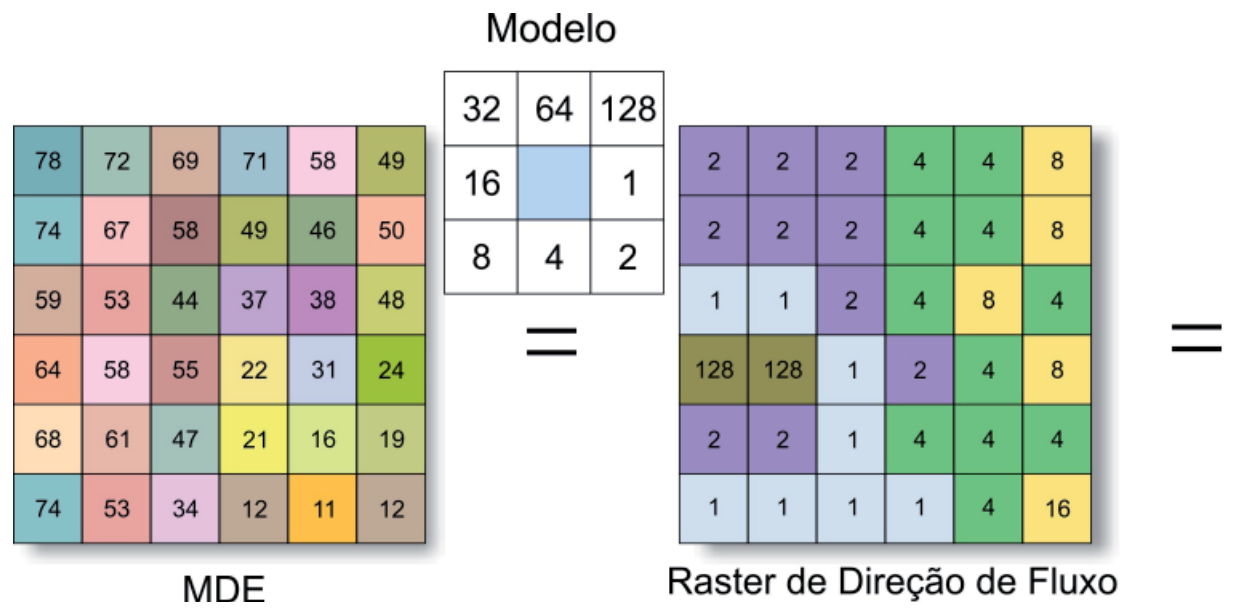

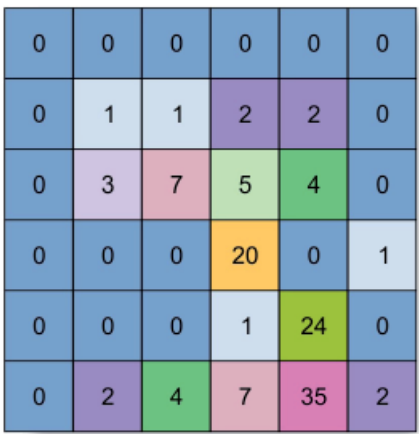

Raster de Fluxo Acumulado

Figura 5 - Etapas da extração de drenagens (Adaptado de ESRI, 2014).

A partir da drenagem gerada foi possível fazer a hierarquização da mesma por meio do software Hydroflow, desenvolvido pelo Laboratório de Geoprocessamento (LabGis) da Faculdade de Geologia da Universidade do Estado do Rio de Janeiro (UERJ), utilizando o método de Strahler. Desse modo, foram delimitadas as sub-bacias de terceira ordem e as sub-bacias alimentadoras do rio principal, calculando o nível de base de cada uma dessas, que corresponde ao valor mínimo de cota altimétrica das mesmas. Por fim, o arquivo vetorial com a delimitações das bacias de terceira ordem em polígonos foi convertido em formato raster e, dessa maneira, cada pixel desse raster localizado na área de uma determinada sub-bacia assumiu o valor do nível de base da mesma, o que permitiu calcular a amplitude altimétrica por meio de uma álgebra de mapas, no qual o MDE da área de estudo foi subtraído pelo raster com os valores de nível de base de cada sub-bacia de terceira ordem.

Finalizando a preparação dos PI e do Banco de Dados, o Mapa de Unidades Geológicas na escala 1:100.000 foi obtido a partir da adequação topológica para a escala de trabalho do Mapa Geológico do Estado do Rio de Janeiro elaborado pela Companhia de Pesquisa de Recursos Minerais (SILVA; CUNHA, 2001), de forma que o mesmo ficasse compatível com os demais 
dados. A escala de levantamento dos dados originais para o mapa do CPRM foi de 1:50.000, contudo o mapa final respeita a escala 1:400.000; sendo assim, foram necessárias correções topológicas, que foram executas com o auxílio dos MDE e das ortofotos do IBGE na escala 1:25.000. Para ser implementado como uma das variáveis para a classificação geomorfológica, o Mapa de Unidades Geológicas na escala 1:100.000 passou por um processo de conversão de dados vetoriais para o formato raster, de forma que para cada classe de unidade geológica foi definido um número para a sua representação em formato matricial (Tabela 1), sendo que a resolução espacial de tal raster foi de 20 metros, assim como os demais PI.

Tabela 1: Valor de pixel definido para cada classe do Mapa de Unidades Geológicas.

\begin{tabular}{l|c}
\hline \multicolumn{1}{c|}{ Classe } & Pixel Value \\
\hline Rochas Alcalinas Cretáceas/Terciárias & 1 \\
Complexo Região de Lagos & 2 \\
Complexo Paraíba do Sul & 3 \\
Complexo Búzios & 4 \\
Complexo Rio Negro & 5 \\
Granitoides Pós-Tectônicos & 6 \\
Suíte Desengano & 7 \\
Represa de Juturnaíba & 8 \\
Depósito Praiais Eólicos e/ou Marinhos & 9 \\
Depósitos Praias Marinhos & 10 \\
Depósitos Flúvio - Lagunares & 11 \\
\hline
\end{tabular}

\subsection{Mapeamento Geomorfológico}

O mapeamento geomorfológico da bacia hidrográfica do rio São João foi efetuado na escala 1:100.000, tendo como base teórica as metodologias propostas por Poçano et al. (1979) e por Ross (1985).

A proposta metodológica de Ross (1985) divide o mapeamento geomorfológico de forma hierárquica em seis táxons, levando em consideração os conceitos de morfoestrutura (que se refere à influência da estrutura geológica na gênese do relevo) e de morfoescultura (vinculado à ação do clima atual e pretérito no modelamento das formas do relevo). O primeiro táxon está relacionado à identificação das unidades morfoestruturais e o segundo na identificação das unidades morfoesculturais; os outros quatro táxons se referem, respectivamente, aos padrões de tipos do relevo, às formas de relevo, às vertentes e às formas atuais.

Para o presente estudo, foram usados os dois pri- meiros táxons de Ross (1985) e, como terceiro táxon, seguiu-se a concepção de sistemas de relevo de Poçano et al. (1979), que consiste na identificação de conjuntos de formas de relevo com textura e padrões semelhantes. Desse modo, o mapeamento foi divido em três táxons: unidades morfoestruturais, unidades morfoesculturais e unidades de relevo. Cada unidade morfoestrutural compreende um conjunto de unidades morfoesculturais, que, por sua vez, compreendem conjuntos de unidades de relevo.

As classes geomorfológicas a serem mapeadas foram definidas com base no mapeamento geomorfológico de Dantas (2001), havendo adequações para melhor atender às características do relevo da área de estudo. Desse modo, a seguinte chave de interpretação (Tabela 2) foi utilizada para identificar as classes geomorfológicas a serem mapeadas.

Tabela 2: Chave de interpretação das feições geomorfológicas:

\begin{tabular}{|c|c|c|c|}
\hline $\begin{array}{c}\text { Unidades } \\
\text { Morfoestruturais }\end{array}$ & $\begin{array}{c}\text { Unidades } \\
\text { Morfoesculturais }\end{array}$ & $\begin{array}{l}\text { Unidades de } \\
\text { Relevo }\end{array}$ & Chave de Interpretação \\
\hline \multirow{2}{*}{$\begin{array}{c}\text { Terrenos } \\
\text { Sedimentares } \\
\text { Cenozoicos }\end{array}$} & \multirow{2}{*}{$\begin{array}{c}\text { Planícies } \\
\text { Sedimentares }\end{array}$} & $\begin{array}{l}\text { Planície } \\
\text { Flúvio } \\
\text { Marinha }\end{array}$ & $\begin{array}{c}\text { Textura lisa; áreas planas; } \\
\text { rugosidade muito baixa; cotas } \\
\text { inferiores a } 2,5 \text { metros; áreas } \\
\text { próximas à costa }\end{array}$ \\
\hline & & $\begin{array}{l}\text { Planície } \\
\text { Aluvial }\end{array}$ & $\begin{array}{l}\text { Textura lisa; áreas planas; } \\
\text { rugosidade muito baixa; áreas } \\
\text { próximas a vertentes e a rios }\end{array}$ \\
\hline \multirow{6}{*}{$\begin{array}{l}\text { Cinturão } \\
\text { Orogênico đo } \\
\text { Attântico }\end{array}$} & \multirow{2}{*}{$\begin{array}{l}\text { Superfícies } \\
\text { Colinosas }\end{array}$} & $\begin{array}{l}\text { Dominio } \\
\text { Suave } \\
\text { Colinoso }\end{array}$ & $\begin{array}{c}\text { Áreas de declividades baixas; } \\
\text { rugosidade baixa; cotas altimétricas } \\
\text { baixas; formas predominantemente } \\
\text { côncavo-convexas de vertentes; } \\
\text { topos suavemente arredondados e } \\
\text { gradiente das vertentes também } \\
\text { suave } \\
\end{array}$ \\
\hline & & $\begin{array}{l}\text { Dominio } \\
\text { Colinoso }\end{array}$ & $\begin{array}{l}\text { Áreas de declividades baixas a } \\
\text { médias; rugosidade baixa a média; } \\
\text { vertentes côncavo-convexas, com } \\
\text { gradiente predominantemente suave; } \\
\text { topos arredondados e alongados }\end{array}$ \\
\hline & \multirow{4}{*}{ Maciços e Serras } & $\begin{array}{l}\text { Maciços } \\
\text { Alcalinos } \\
\text { Intrusivos }\end{array}$ & $\begin{array}{l}\text { Áreas com declividades altas e } \\
\text { muito altas; rugosidade alta e muito } \\
\text { alta; altas cotas altimétricas; } \\
\text { litologia com predominância de } \\
\text { rochas alcalinas intrusivas }\end{array}$ \\
\hline & & $\begin{array}{l}\text { Maciços } \\
\text { Costeiros }\end{array}$ & $\begin{array}{l}\text { Áreas de declividades altas; } \\
\text { rugosidade média a alta; topos } \\
\text { alinhados a arredondados; altas } \\
\text { cotas altimétricas }\end{array}$ \\
\hline & & Degraus & $\begin{array}{c}\text { Áreas de declividades médias; } \\
\text { rugosidade média; vertentes } \\
\text { predominantemente retilineas a } \\
\text { côncavas, topos de cristas alinhados, } \\
\text { aguçados ou levemente } \\
\text { arredondados }\end{array}$ \\
\hline & & $\begin{array}{l}\text { Domínio } \\
\text { Serrano }\end{array}$ & $\begin{array}{l}\text { Áreas que abrigam escarpas e } \\
\text { relevos serranos; cotas altimétricas } \\
\text { altas ou muito altas; declividades } \\
\text { altas e muito altas; rugosidade alta e } \\
\text { muito alta; gradiente das vertentes } \\
\text { elevado e muito elevado, } \\
\text { apresentando geometria retilinea } \\
\text { com topos triangulares; } \\
\text { frequentemente, com paredões de } \\
\text { rochas expostas }\end{array}$ \\
\hline
\end{tabular}




\subsubsection{Métodos para Classificação}

O método para classificação envolveu as etapas do fluxograma apresentado na Figura 6, sendo utilizadas as seguintes variáveis como dados de entrada: MDE, amplitude altimétrica, declividade, curvatura vertical, módulo da curvatura vertical, e mapa de unidades geológicas.

\subsubsection{Segmentação Multirresolução}

Assim como demanda a classificação de imagem por OBIA, a segmentação se caracteriza pela multirresolução, sendo aplicada a partir do nível mais geral até o nível mais detalhado. Desta forma, a segmentação multirresolução foi estruturada de acordo com a hierarquia taxonômica proposta para o presente trabalho, sempre buscando atribuir pesos a cada variável utilizada, visando otimizar os resultados em cada nível de segmentação.
Para a classificação das unidades morfoestruturais foi levada em consideração, principalmente, a declividade, a que foi atribuído peso 2 (dois) nesse primeiro nível de segmentação, sendo que as demais variáveis foram definidas como possuindo peso 1 (um). Tal seleção de pesos é justificada pelo fato de a declividade, na área de estudo, ser indicadora de áreas sedimentares e não sedimentares.

Na classificação das unidades morfoesculturais, as variáveis declividade e amplitude altimétrica foram definidas como possuindo peso 2 (dois) e as demais variáveis permaneceram como peso 1 (um) na segmentação da Unidade Morfoestrutural Cinturão Orogênico do Atlântico.

Por fim, no último táxon, na classificação das unidades de relevo, foram executadas três segmentações: na segmentação da Unidade Morfoescultural Planície Sedimentares priorizou-se a variável altimetria; na segmentação da Unidade Morfoescultural Superfícies

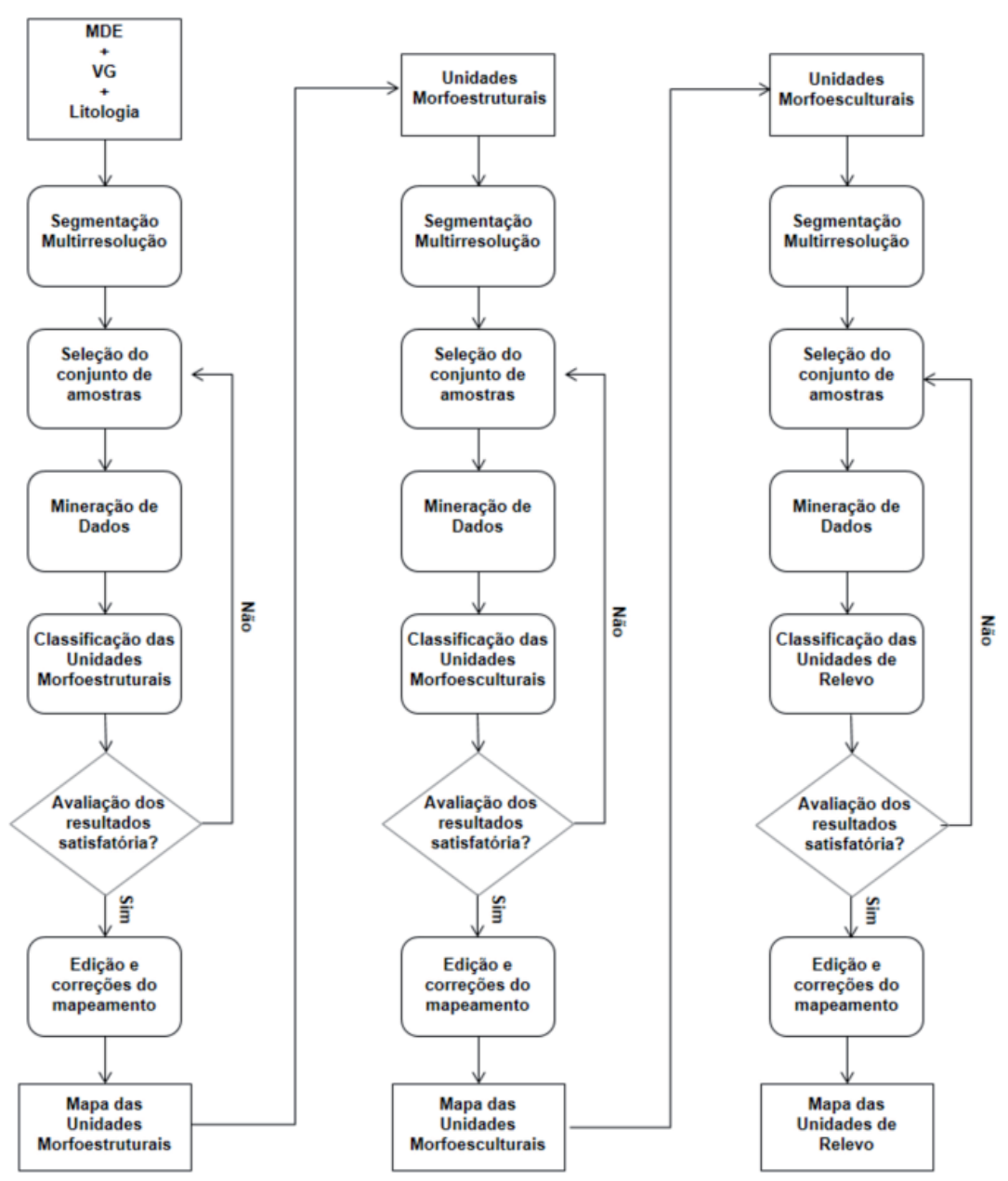

Figura 6 - Fluxograma das etapas da classificação geomorfológica. 
Colinosas foram priorizadas as variáveis declividade e amplitude altimétrica; e na segmentação da Unidade Morfoescultural Maciços e Serras foram priorizadas as variáveis unidades geológicas, altimetria e declividade. Em todos os casos citados, entende-se priorizar como atribuir peso 2 (dois) a determinada variável, de forma que, para as demais variáveis, foi atribuído peso 1 (um).

\subsubsection{Seleção do Conjunto Amostral}

A seleção do conjunto amostral é uma etapa fundamental para se obter bons resultados oriundos da mineração de dados. Em vista disso, a seleção de amostras foi feita com base na chave de interpretação já apresentada anteriormente (Tabela 2), levando em consideração a interpretação visual do relevo sombreado, ortofotos e levantamentos de campo.

Foram coletados somente, os segmentos/objetos de que não se tinha dúvidas quanto a sua classificação e, portanto, segmentos/objetos duvidosos e de transição não foram selecionados para comporem o conjunto de amostras. É importante destacar que as amostras foram selecionadas por toda a área de estudo, no intuito de tornar o conjunto de amostras o mais possivelmente representativo de cada classe.

Uma vez selecionado o conjunto de amostras, foram exportadas tabelas contendo a média de cada variável de cada segmento/objeto selecionado para a realização da mineração de dados. Optou-se por utilizar somente a média, pois testes prévios com a mineração de dados mostraram que a média das variáveis utilizadas nesse trabalho era suficiente para se obter bons resultados quanto à classificação desejada.

\subsubsection{Mineração de dados}

Na etapa de mineração de dados optou-se por utilizar o algoritmo C4.5, elaborado por Quinlan (1993). O algoritmo C4.5 é amplamente testado e validado e o mesmo já comprovou a sua capacidade de obter bons resultados em trabalhos de sensoriamento remoto (FERNANDES, 2013). Basicamente, o algoritmo C4.5 examina todos os atributos previsores candidatos, seleciona aquele que maximiza a taxa de ganho para rotular o nó atual da árvore e repete o processo sucessivamente para dar continuação à construção da árvore de decisão até que todas as instâncias do conjunto de treinamento sejam classificadas (VIEIRA, 2010).
Os conjuntos de amostras exportados no formato de tabela foram inseridos no software WEKA para a execução da mineração de dados, obtendo assim os modelos de conhecimento em forma de árvores de decisão para serem usados na classificação geomorfológica.

É importante destacar que no processo de mineração de dados há alguns parâmetros no algoritmo que são passíveis de alteração pelo usuário. Alterações nesses parâmetros resultam em diferentes árvores de decisão, impactando em seu tamanho e complexidade. Em vista disso, uma gama variada de testes foi feita alterando esses parâmetros, sendo que os parâmetros usados foram os que obtiveram os resultados mais adequados em relação à complexidade, tamanho e capacidade de classificações corretas da árvore de decisão resultante.

\subsubsection{Classificação}

Na classificação geomorfológica, as árvores de decisão resultantes da mineração de dados foram implementadas no programa eCognition 8.7. Por fim, os erros de classificação foram corrigidos com a utilização das ferramentas de classificação e edição manual. Vale ressaltar que tais erros ocorreram em poucos casos e, na maior parte das vezes, foram resultantes de imperfeições na segmentação.

\section{Resultados}

\subsection{Mapeamento das Unidades Morfoestruturais}

A primeira etapa do mapeamento está vinculada ao primeiro táxon proposto por Ross (1985) e, assim sendo, foram mapeadas as seguintes unidades morfoestruturais: Cinturão Orogênico de Atlântico, que é composta pelo relevo oriundo da Faixa de Dobramentos Ribeira; e Terrenos Sedimentares Cenozoicos, caracterizada por depósitos sedimentares relacionados a processos denudacionais das encostas, processos fluviais e aos processos referentes às mudanças do nível do mar no Quaternário.

Na mineração de dados, a declividade se mostrou substancialmente eficiente para diferenciar as duas unidades morfoestruturais, de modo que sua média foi apontada como único parâmetro necessário para tal diferenciação (Figura 7).

Após a construção da árvore de decisão, o WEKA testa a mesma a partir do mesmo conjunto amostral utilizado para sua elaboração e, dessa forma, é possí- 
vel identificar instâncias amostrais que não estariam classificadas corretamente pela árvore de decisão em questão. O relatório desse teste (Tabelas 3 e 4) expressa a adequação da árvore de decisão obtida para diferen- ciar as classes de unidades morfoestruturais. Segundo tal relatório, 98,7\% das instâncias foram classificadas corretamente pela árvore de decisão, alcançando um índice Kappa de 0,9673.

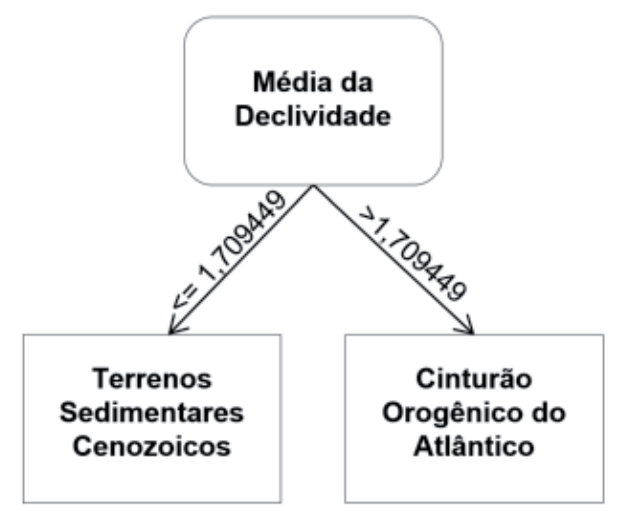

Figura 7 - Árvore de decisão obtida para o mapeamento de unidades morfoestruturais.

Tabela 3: Relatório de mineração de dados - Unidades Morfoestruturais.

\begin{tabular}{c|c|c}
\hline & $\begin{array}{c}\text { Número de } \\
\text { Instâncias }\end{array}$ & Percentagem \\
\hline $\begin{array}{c}\text { Instâncias Classificadas } \\
\text { Corretamente }\end{array}$ & 459 & $98,7 \%$ \\
\hline $\begin{array}{c}\text { Instâncias Classificadas } \\
\text { Incorretamente }\end{array}$ & 6 & $1,3 \%$ \\
\hline Indice Kappa & \multicolumn{2}{|c}{0,9673} \\
\hline
\end{tabular}

Tabela 4: Matriz de confusão - Unidades Morfoestruturais.

\begin{tabular}{c|c|c}
\hline & \multicolumn{2}{|c}{ Classificado como: } \\
\cline { 2 - 3 } & $\begin{array}{c}\text { Cinturão Orogênico do } \\
\text { Atlântico }\end{array}$ & $\begin{array}{c}\text { Terrenos Sedimentares } \\
\text { Cenozoicos }\end{array}$ \\
\hline $\begin{array}{c}\text { Cinturão Orogênico do } \\
\text { Attântico }\end{array}$ & 336 & 2 \\
\hline $\begin{array}{c}\text { Terrenos Sedimentares } \\
\text { Cenozoicos }\end{array}$ & 4 & 123 \\
\hline
\end{tabular}

A classificação das unidades morfoestruturais na área de estudo a partir da árvore de decisão obtida (Figura 8) gerou pouquíssimos erros, sendo que a maior parte deles ocorreu em áreas planas com presença de vegetação de grande porte que foram representadas pelo MDE como áreas com maiores declividades (Figura 9); tais erros, contudo, foram corrigidos na etapa de edição. Vale ressaltar que somente $1,4 \%$ dos objetos gerados foram editados.

A eficiência da árvore de decisão é explicada pela grande diferença entre o relevo das duas classes mapeadas, pois a Unidade Morfoestrutural Terrenos Sedimentares Cenozoicos apresenta um relevo com menos rugosidade e mais plano, enquanto a Unidade Morfoestrutural Cinturão Orogênico do Atlântico apre- senta um relevo variando desde rugosidades mais suaves até altas rugosidades, caracterizados por terrenos mais acidentados, logo com maiores declividades.

\subsection{Mapeamento das Unidades Morfoesculturais}

No mapeamento do segundo táxon, foi mapeada somente uma unidade morfoescultural (Planícies Sedimentares) na Unidade Morfoestrutural Terrenos Sedimentares Cenozoicos; logo não foi necessária a geração de uma árvore de decisão para classificar tal unidade morfoescultural.

Já na Unidade Morfoestrutural Cinturão Orogênico do Atlântico foram mapeadas duas unidades morfoesculturais: Maciços e Serras; e Superfícies Colinosas. A primeira consiste em terrenos mais acidentados e com maiores altitudes, e a segunda se caracteriza por ser uma ampla região colinosa, com topografia uniforme e topos nivelados de baixa amplitude de relevo.

Para a mineração de dados no segundo táxon foram selecionadas 441 amostras, sendo que se obteve uma árvore de decisão mais complexa do que no primeiro táxon. A árvore de decisão obtida identificou como parâmetros de classificação: a média da declividade; média da altimetria; média da amplitude altimétrica; e média da curvatura vertical (Figura 10). O relatório do teste gerado pelo WEKA (tabelas 5 e 6 ) mostra que $95,70 \%$ das instâncias foram classificadas corretamente pela árvore de decisão, alcançando um índice Kappa de 0,9004. 
Girão R. S. et al.

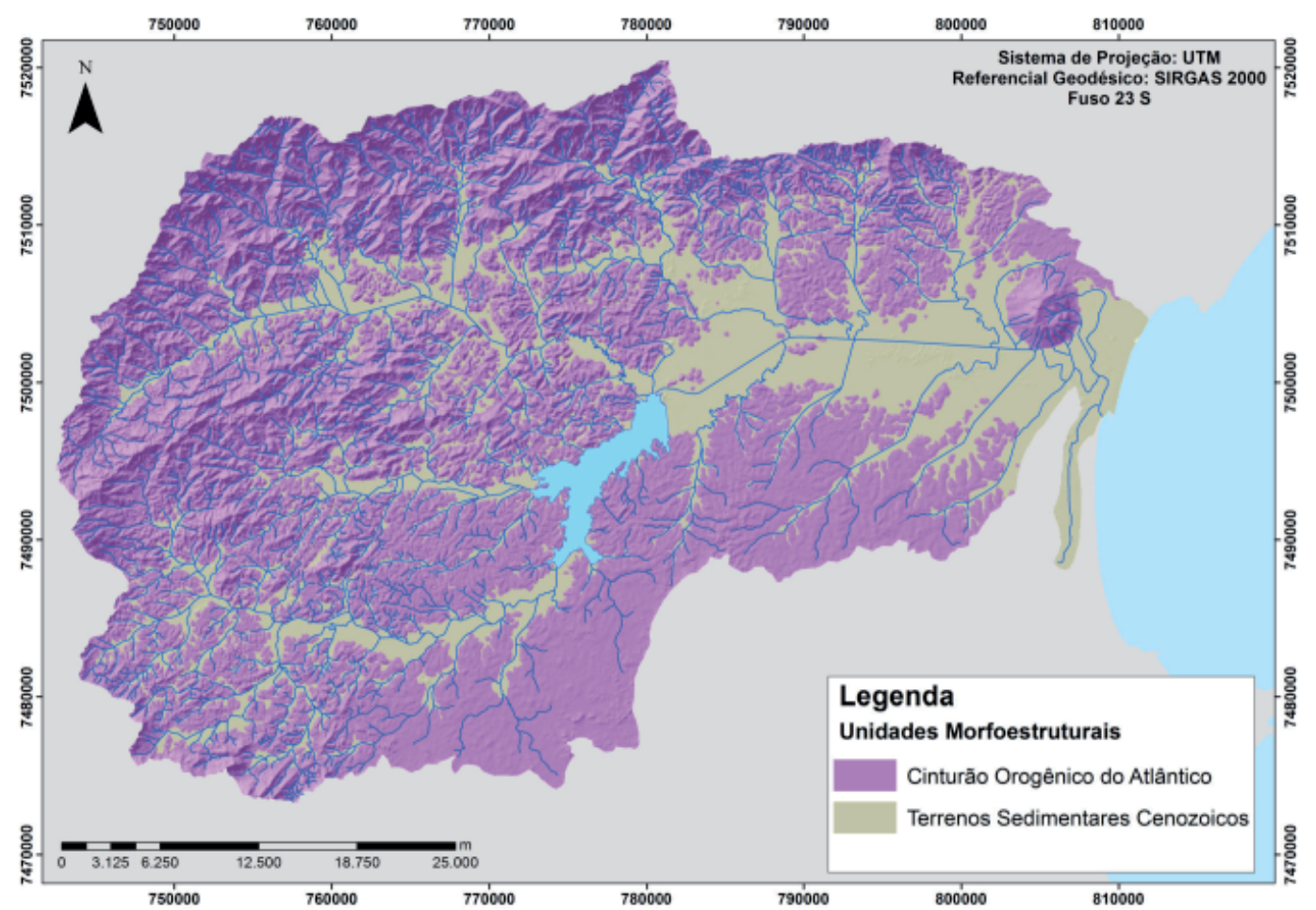

Figura 8 - Mapa de unidades morfoestruturais da Bacia Hidrográfica do rio São João (RJ).
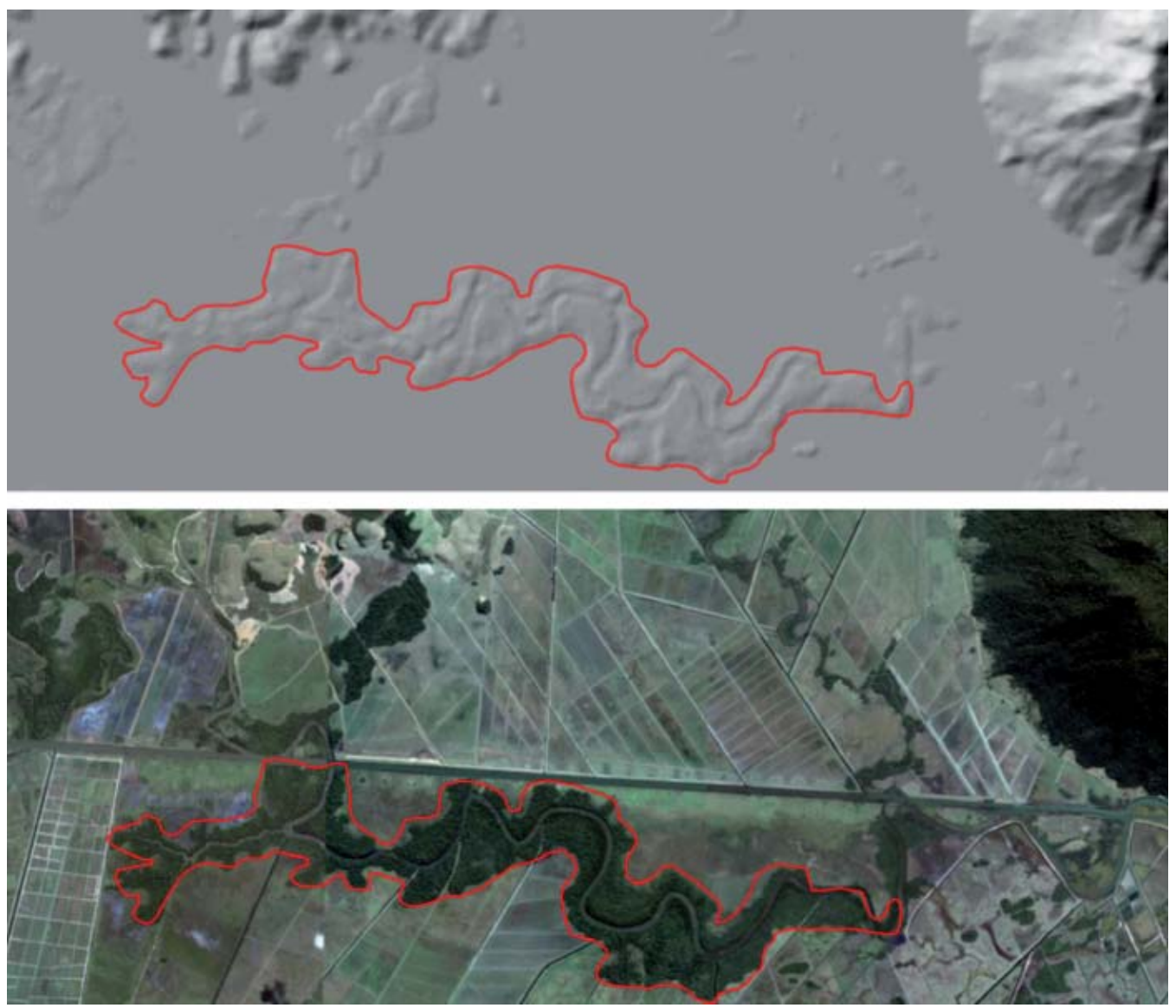

Figura 9 - Exemplo de áreas planas com presença de vegetação de grande porte que foram representadas pelo MDE, gerando erros na classificação, corrigidos na etapa de edição. 


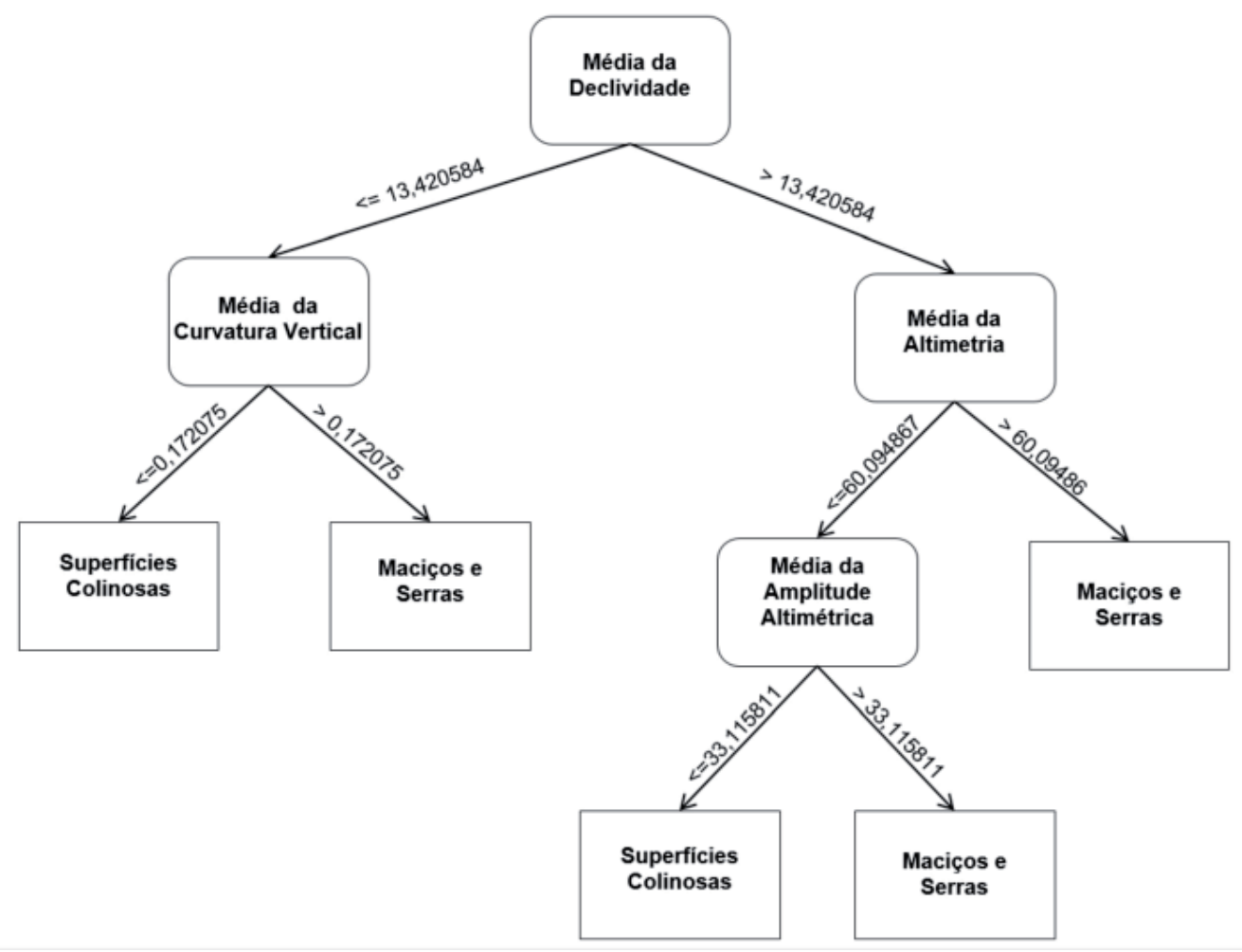

Figura 10 - Árvore de decisão obtida para o mapeamento das unidades morfoesculturais Maciços e Serras, e Superfícies Colinosas.

Tabela 5: Relatório de mineração de dados - Unidades Morfoesculturais (Maciços e Serras, e Superfícies Colinosas).

\begin{tabular}{c|c|c}
\hline & $\begin{array}{c}\text { Número de } \\
\text { Instâncias }\end{array}$ & Percentagem \\
\hline $\begin{array}{c}\text { Instâncias Classificadas } \\
\text { Corretamente }\end{array}$ & 422 & $95,7 \%$ \\
\hline $\begin{array}{c}\text { Instâncias Classificadas } \\
\text { Incorretamente }\end{array}$ & 19 & $4,3 \%$ \\
\hline Indice Kappa & \multicolumn{2}{|c}{0,9004} \\
\hline
\end{tabular}

Tabela 6: Matriz de Confusão-Unidades Morfoesculturais (Maciços e Serras, e Superfícies Colinosas).

\begin{tabular}{c|c|c}
\hline \multirow{2}{*}{} & \multicolumn{2}{|c}{ Classificado como: } \\
\cline { 2 - 3 } & Maciços e Serras & Superficies Colinosas \\
\hline Maciços e Serras & 292 & 7 \\
\hline Superficies Colinosas & 12 & 130 \\
\hline
\end{tabular}

Nesse nível taxonômico, foi necessário um maior trabalho na etapa de edição e correções de erros do que no nível taxonômico anterior: 5,2\% dos objetos passaram por correções, contudo as mesmas foram executadas de forma rápida e pouco trabalhosa. Desse modo, a classificação obtida por meio da árvore de decisão gerada foi satisfatória (Figura 11), resultando em pouquíssimos erros, na maioria sendo causados por imperfeições na segmentação. Algumas colinas com maiores altitudes e levemente mais dissecadas foram classificadas de forma equivocada, contudo tais ocorrências foram raras, evidenciando a eficiência da árvore de decisão.

\subsection{Mapeamento das Unidades de Relevo}

No mapeamento do terceiro táxon, foram mapeadas quatro unidades de relevo na Unidade Morfoescultural Maciços e Serras: Domínio Serrano, que consiste em um proeminente alinhamento serrano; Degraus, que são patamares litoestruturais, com vertentes predominantemente retilíneas a côncavas; Maciços Costeiros, que consiste em um conjunto de maciços montanhosos relativamente alinhados; e Maciços Alcalinos Intrusivos, que se caracteriza como conjunto de maciços montanhosos de rochas ígneas alcalinas.

Na etapa de mineração de dados relativa à classificação das unidades de relevo subordinadas à Unidade Morfoescultural Maciços e Serras, foram selecionados somente 40 objetos para compor o conjunto amostral, pois a segmentação gerou poucos objetos, sendo que os mesmos eram relativamente grandes. De acordo com a árvore de decisão obtida, a média da altimetria foi utilizada para identificar a Unidade de Relevo Degraus 


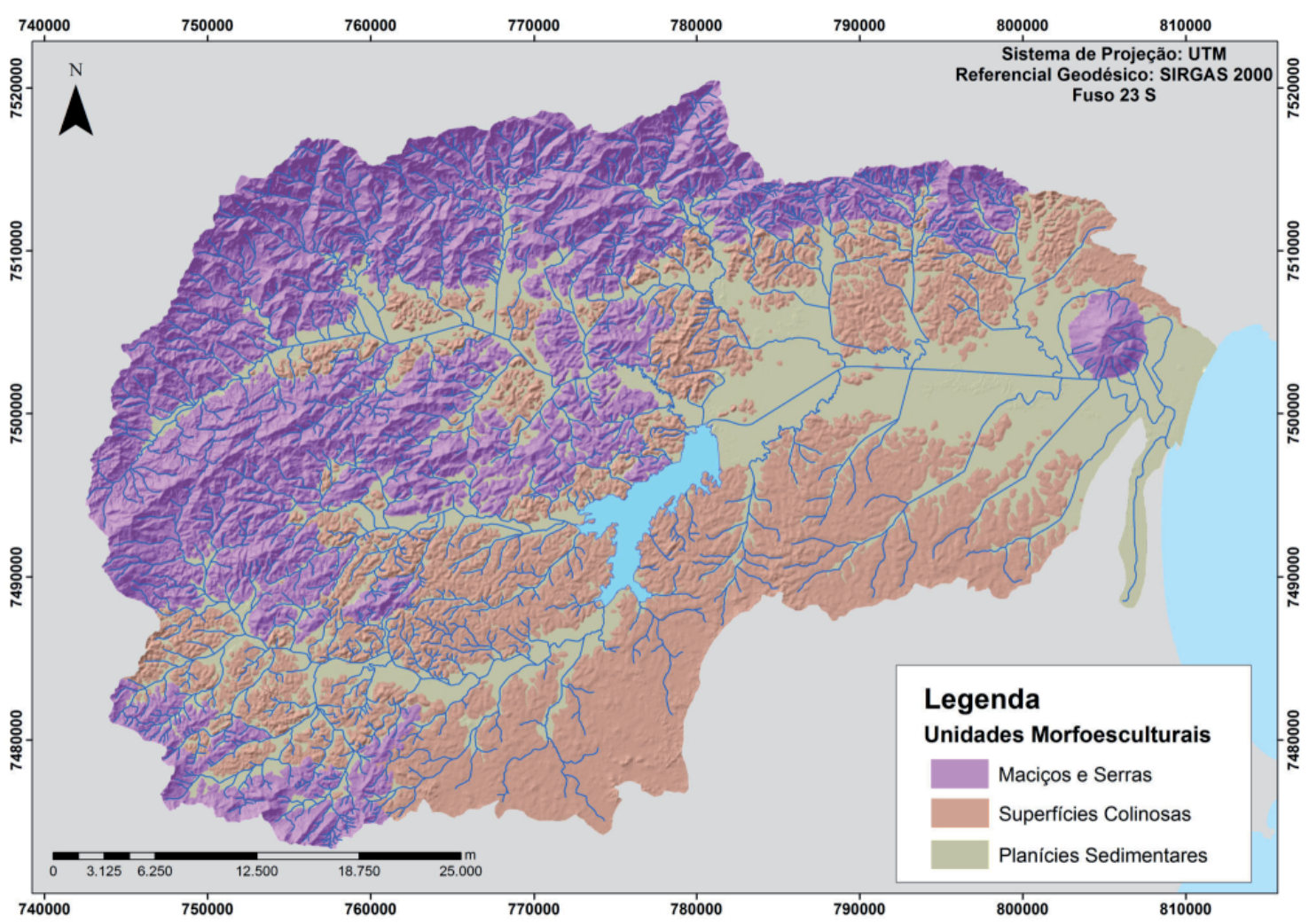

Figura 11 - Mapa de unidades morfoesculturais da Bacia Hidrográfica do rio São João (RJ).

das demais unidades; o substrato geológico (unidades geológicas) diferenciou a Unidade de Relevo Maciços Alcalinos das demais; e a média da declividade diferenciou as unidades de relevo Maciços Costeiros e Domínio Serrano (Figura 12).

O relatório do teste gerado pelo WEKA (tabelas 7 e 8) mostra que $80,5 \%$ das instâncias foram classificadas corretamente pela árvore de decisão, alcançando um índice Kappa de 0,6586. Tal resultado é bem inferior em relação aos obtidos anteriormente, sendo explicado, principalmente, pela dificuldade de diferenciar a Unidade de Relevo Maciços Costeiros das unidades de relevo Domínio Serrano e Degraus. Essa dificuldade é vista na matriz de confusão (Tabela 8), que mostra que, dos cinco objetos que foram selecionados como amostras da Unidade de Relevo Maciços Costeiros, três foram classificados de forma incorreta pela árvore de decisão.

Apesar de a etapa de mineração de dados não apresentar resultados tão satisfatórios, a árvore de decisão mostrou ser adequada para a classificação, de forma que só foi preciso algumas edições e correções (em 20,7\% dos objetos), principalmente na classificação da Unidade de Relevo Maciços Costeiros; contudo tais edições e correções foram feitas de forma rápida e simples, devido à quantidade e tamanho dos objetos.

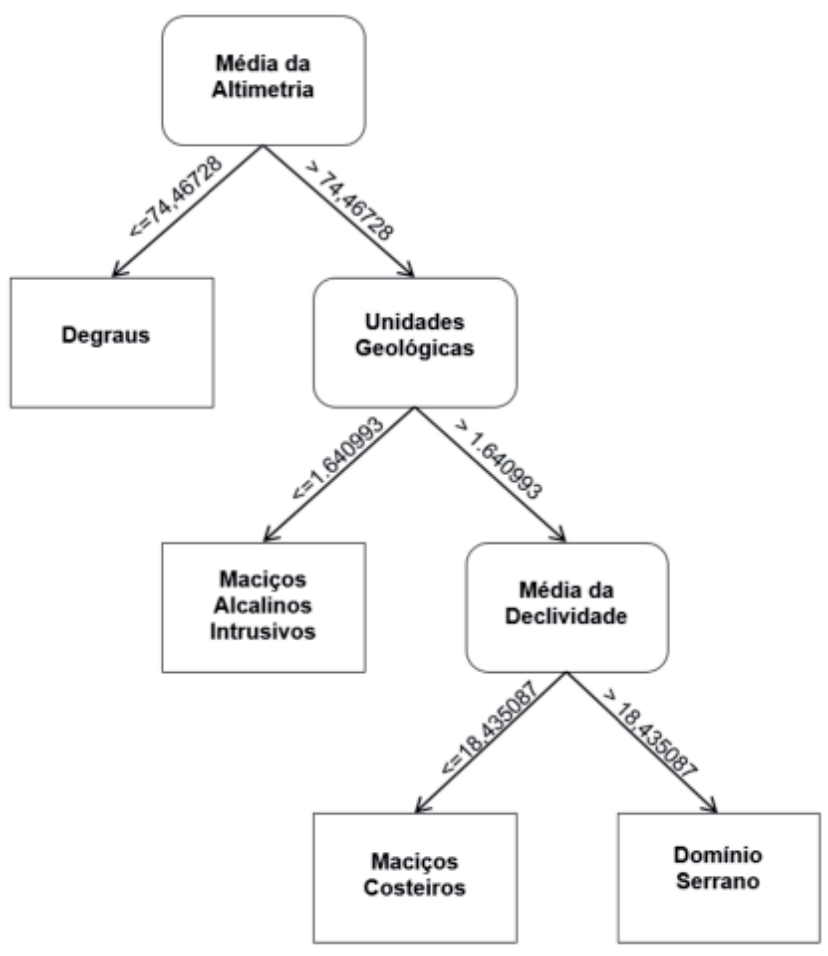

Figura 12 - Árvore de decisão obtida para o mapeamento das unidades de relevo Domínio Serrano, Degraus, Maciços Costeiros, e Maciços Alcalinos Intrusivos 
Tabela 7: Relatório de Mineração de Dados - Unidades de Relevo (Domínio Serrano, Degraus, Maciços Costeiros, e Maciços Alcalinos Intrusivos).

\begin{tabular}{c|c|c}
\hline & $\begin{array}{c}\text { Número de } \\
\text { Instâncias }\end{array}$ & Percentagem \\
\hline $\begin{array}{c}\text { Instâncias Classificadas } \\
\text { Corretamente }\end{array}$ & 32 & $80,5 \%$ \\
\hline $\begin{array}{c}\text { Instâncias Classificadas } \\
\text { Incorretamente }\end{array}$ & 8 & $19,5 \%$ \\
\hline Indice Kappa & \multicolumn{2}{|c}{0,6586} \\
\hline
\end{tabular}

Tabela 8: Matriz de Confusão - Unidades de Relevo (Domínio Serrano, Degraus, Maciços Costeiros, e Maciços Alcalinos Intrusivos).

\begin{tabular}{c|c|c|c|c}
\hline & \multicolumn{4}{|c}{ Classificado como: } \\
\cline { 2 - 5 } & Degraus & $\begin{array}{c}\text { Domínio } \\
\text { Serrano }\end{array}$ & $\begin{array}{c}\text { Maciços } \\
\text { Alcalinos } \\
\text { Intrusivos }\end{array}$ & $\begin{array}{c}\text { Maciços } \\
\text { Costeiros }\end{array}$ \\
\hline Degraus & 8 & 2 & 0 & 0 \\
\hline Dominio Serrano & 1 & 19 & 0 & 1 \\
\hline $\begin{array}{c}\text { Maciços Alcalinos } \\
\text { Intrusivos }\end{array}$ & 0 & 0 & 3 & 1 \\
\hline Maciços Costeiros & 1 & 2 & 0 & 2 \\
\hline
\end{tabular}

Na Unidade Morfoescultural Superfícies Colinosas foram mapeadas duas unidades de relevo: Domínio Colinoso, caracterizado por um conjunto de colinas com topos arredondados; e Domínio Suave Colinoso, que consiste em terrenos compostos de colinas suaves com pequenas altitudes.

Foram selecionados 276 objetos para compor o conjunto amostral. Segundo a árvore de decisão obtida, a média de declividade e a média do módulo da curvatura vertical foram os melhores diferenciadores dessas duas classes de unidades de relevo (Figura 13).

O relatório do teste gerado pelo WEKA (tabelas 9 e 10) mostra que $96,4 \%$ das instâncias foram classificadas corretamente pela árvore de decisão, alcançando um índice Kappa de 0,9213. A classificação obtida a partir da árvore de decisão foi bem satisfatória, ocorrendo alguns poucos erros em áreas de transição, como já era esperado, pois nessas áreas a diferenciação entre as unidades de relevo Domínio Colinoso e Domínio Suave Colinoso é uma tarefa árdua até mesmo por meio de classificação visual de ortofotos e relevo sombreado. Destaca-se que foram necessárias correções em apenas 3,9\% dos objetos.

Por fim, na Unidade Morfoescultural Planícies Sedimentares foram mapeadas duas unidades de relevo: Planície Aluvial e Planície Flúvio-Marinha. A primeira é caracterizada por apresentar feições associadas a processos continentais aluviais, como terraços fluviais, e a segunda é caracterizada pela

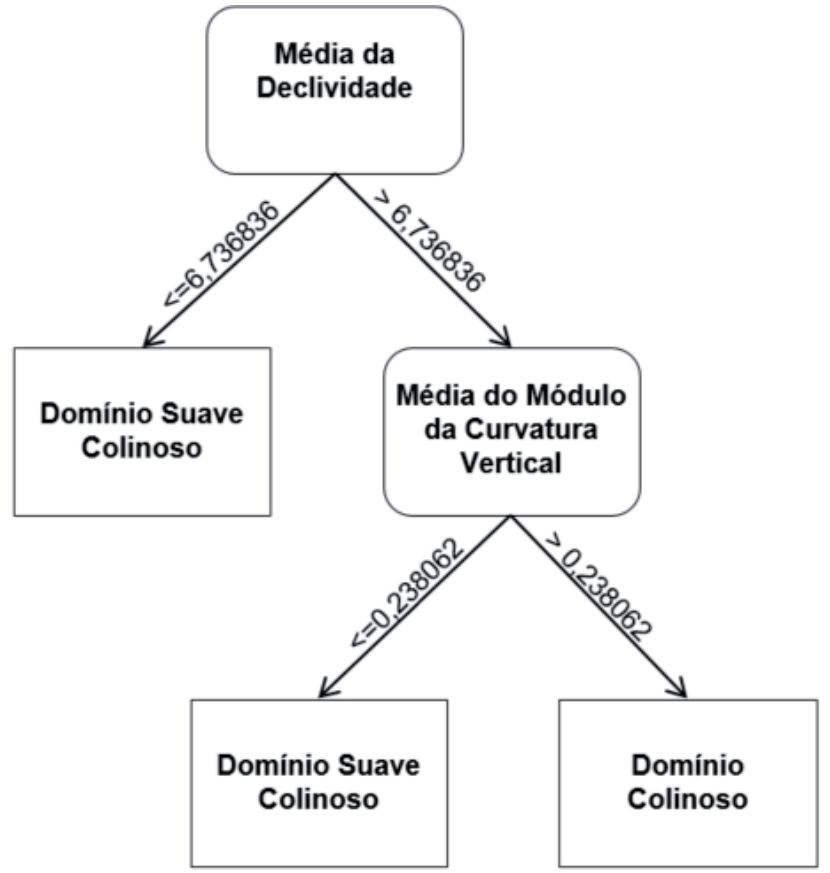

Figura 13 - Árvore de decisão obtida para o mapeamento das unidades de relevo Domínio Colinoso e Domínio Suave Colinoso.

Tabela 9: Relatório de mineração de dados - Unidades de Relevo (Domínio Colinoso e Domínio Suave Colinoso).

\begin{tabular}{c|c|c}
\hline & $\begin{array}{c}\text { Número de } \\
\text { Instâncias }\end{array}$ & Percentagem \\
\hline $\begin{array}{c}\text { Instâncias Classificadas } \\
\text { Corretamente }\end{array}$ & 266 & $96,4 \%$ \\
\hline $\begin{array}{c}\text { Instâncias Classificadas } \\
\text { Incorretamente }\end{array}$ & 10 & $3,6 \%$ \\
\hline Indice Kappa & \multicolumn{2}{|c}{0,9213} \\
\hline
\end{tabular}

Tabela 10: Matriz de confusão - Unidades de Relevo (Domínio Colinoso e Domínio Suave Colinoso).

\begin{tabular}{c|c|c}
\hline \multirow{2}{*}{} & \multicolumn{2}{|c}{ Classificado como: } \\
\cline { 2 - 3 } & Dominio Colinoso & Dominio Suave Colinoso \\
\hline Dominio Colinoso & 172 & 03 \\
\hline Dominio Suave Colinoso & 07 & 94 \\
\hline
\end{tabular}

sedimentação costeira junto a depósitos sedimentares continentais, ou seja, são terrenos sedimentares transicionais entre o ambiente continental e o ambiente costeiro.

Na classificação dessas duas unidades de relevo não se seguiu o método executado nas demais classificações (mineração de dados), pois o aspecto mais relevante para a diferenciação dessas duas unidades é referente à variação relativa do nível do mar, que é uma informação essencialmente qualitativa, apesar de ter valores quantitativos como resultado.

Desse modo, as unidades de relevo Planície Alu- 
vial e Planície Flúvio-Marinha foram diferenciadas pela cota altimétrica de 2,5 metros, correspondente ao nível máximo transgressivo do mar no Quaternário tardio para a região, de acordo com Dias (2009). Desta forma, todas as áreas na Unidade Morfoescultural Planícies Sedimentares acima de 2,5 metros de altitude foram classificadas como Unidade de Relevo Planície Aluvial e todas as áreas com cotas altimétricas até 2,5 metros foram classificadas como Unidade de Relevo Planície Flúvio-Marinha (Figura 14).

A partir das árvores de decisão obtidas para a classificação das unidades de relevo nas três unidades morfoesculturais (Figuras 12, 13 e 14) foi gerado o mapa de unidades de relevo da BHSJ (Figura 15).

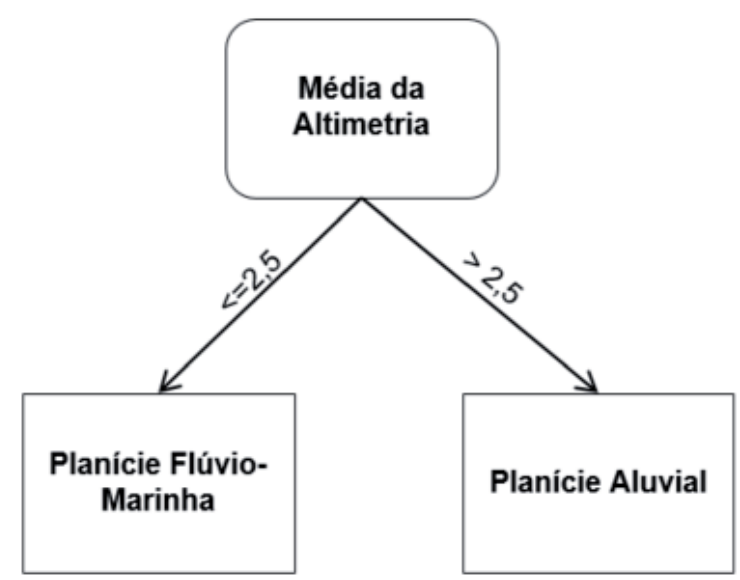

Figura 14 - Árvore de decisão obtida para o mapeamento das unidades de relevo Planície Aluvial e Planície Flúvio-Marinha

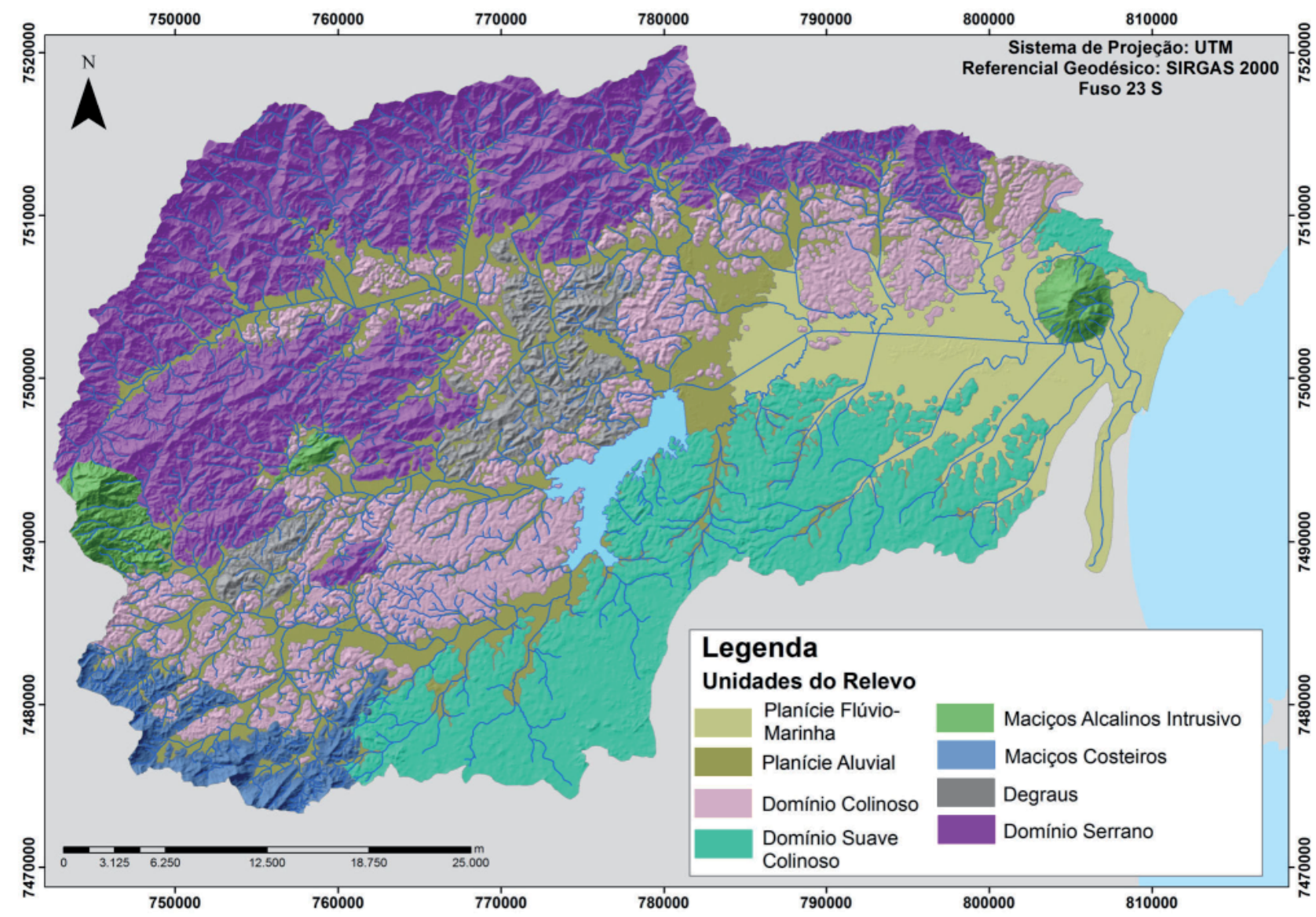

Figura 15 - Mapa de unidades de relevo da Bacia Hidrográfica do rio São João (RJ). 


\subsection{Caracterização das Unidades de Relevo}

As ferramentas de SIG possibilitaram a construção de um quadro de caracterização das unidades de relevo mapeadas (Tabela 11), que junto ao mapa de unidades de relevo da BHSJ (Figura 15), permitiu a análise e descrição geomorfométrica dessas unidades de relevo.

A Unidade de Relevo Domínio Serrano de relevo localiza-se na porção norte, sendo a unidade de relevo com maior abrangência espacial na área de estudo, possuindo também os maiores valores em relação à altimetria, amplitude altimétrica e declividade.

A Unidade de Relevo Degraus ocorre na porção central e possui cotas altimétricas variando de 74 a 262 metros e declividade variando entre $7^{\circ}$ e $25^{\circ}$, se destacando topograficamente do Domínio Colinoso.

A Unidade de Relevo Maciços Costeiros localiza-se na porção sul e caracteriza-se por um relevo acidentado, com altitudes moderadas a elevadas, alcançando cotas de até 610 metros. Tal unidade de relevo apresenta declividade variando entre $7^{\circ}$ e $24^{\circ}$.

A Unidade de Relevo Maciço Alcalino Intrusi- vo caracteriza-se por feições isoladas, apresentando cotas altimétricas e declividades somente inferiores à Unidade de Relevo Domínio Serrano, dessa forma, destaca-se topograficamente e morfologicamente das feições adjacentes.

A Unidade de Relevo Domínio Colinoso aparece em diferentes porções da BHSJ e é caracterizada por colinas com altitudes médias, variando de cerca de 20 a 150 metros. A declividade dessa unidade varia de cerca de $4^{\circ}$ a $17^{\circ}$.

A Unidade de Relevo Domínio Suave Colinoso abrange a porção sul e sudeste da BHSJ, consistindo em um conjunto de colinas com pequenas altitudes (cotas não superiores a 75 metros).

A Unidade de Relevo Planície Aluvial abrange as áreas mais planas e interioranas da BHSJ, caracterizando-se por uma topografia muito suave, com declividades e cotas altimétricas muito baixas.

Por fim, a Unidade de Relevo Planície Flúvio-Marinha abrange as áreas planas, com cotas inferiores a 2,5 metros e próximas à região costeira da BHSJ.

Tabela 11: Quadro de caracterização das unidades de relevo mapeadas na BHSJ.

\begin{tabular}{|c|c|c|c|c|c|c|c|c|c|c|}
\hline \multirow{2}{*}{$\begin{array}{c}\text { Unidades } \\
\text { Morfoestruturais }\end{array}$} & \multirow{2}{*}{$\begin{array}{c}\text { Unidades } \\
\text { Morfoesculturais }\end{array}$} & \multirow{2}{*}{$\begin{array}{l}\text { Unidades } \\
\text { de Relevo }\end{array}$} & \multirow{2}{*}{$\begin{array}{l}\text { Área - } \\
\text { Percentual em } \\
\text { relação a área } \\
\text { de estudo }\end{array}$} & \multicolumn{2}{|c|}{$\begin{array}{l}\text { Altimetria } \\
\quad(\mathrm{m})\end{array}$} & \multicolumn{2}{|c|}{$\begin{array}{l}\text { Amplitude } \\
\text { Altimétrica } \\
\text { (m) }\end{array}$} & \multirow{2}{*}{$\begin{array}{c}\text { Faixa de } \\
\text { Declividade } \\
\text { Dominante }\left({ }^{\circ}\right)\end{array}$} & \multirow{2}{*}{$\begin{array}{c}\text { Faixa de } \\
\text { Curvatura } \\
\text { Vertical } \\
\text { Dominante }\left({ }^{\circ} / \mathrm{m}\right)\end{array}$} & \multirow{2}{*}{$\begin{array}{l}\text { Faixa do Módulo } \\
\text { Curvatura } \\
\text { Vertical } \\
\text { Dominante }\left({ }^{\circ} / \mathrm{m}\right)\end{array}$} \\
\hline & & & & Min & Max & Min & $\operatorname{Max}$ & & & \\
\hline \multirow{2}{*}{$\begin{array}{l}\text { Terrenos } \\
\text { Sedimentares } \\
\text { Cenozoicos }\end{array}$} & \multirow{2}{*}{$\begin{array}{c}\text { Planicies } \\
\text { Sedimentares }\end{array}$} & $\begin{array}{l}\text { Planicie } \\
\text { Flúvio- } \\
\text { Marinha }\end{array}$ & 10,21 & 0 & 2,5 & 0 & 0 & $0-1,23$ & $-0,10-0,11$ & $0,00-0,13$ \\
\hline & & $\begin{array}{c}\text { Planicie } \\
\text { Aluvial }\end{array}$ & 16,40 & 2,5 & 60 & 0 & 25 & $0-2,95$ & $-0,16-0,24$ & $0,00-0,28$ \\
\hline \multirow{6}{*}{$\begin{array}{l}\text { Cinturão } \\
\text { Orogênico do } \\
\text { Atlântico }\end{array}$} & \multirow{2}{*}{$\begin{array}{l}\text { Superficies } \\
\text { Colinosas }\end{array}$} & $\begin{array}{l}\text { Dominio } \\
\text { Suave } \\
\text { Colinoso } \\
\end{array}$ & 17,72 & 18 & 75 & 14 & 70 & $0,98-7,41$ & $-0,22-0,26$ & $0,00-0,34$ \\
\hline & & $\begin{array}{l}\text { Domínio } \\
\text { Colinoso }\end{array}$ & 16,65 & 20 & 150 & 17 & 145 & $3,95-17,69$ & $-0,44-0,56$ & $0,00-0,71$ \\
\hline & \multirow{4}{*}{ Maciços e Serras } & $\begin{array}{l}\text { Maciços } \\
\text { Alcalinos } \\
\text { Intrusivos }\end{array}$ & 2,57 & 325 & 925 & 318 & 880 & $10,82-27,82$ & $-0,71-0,78$ & $0,00-1,01$ \\
\hline & & $\begin{array}{l}\text { Maciços } \\
\text { Costeiros }\end{array}$ & 3,06 & 215 & 610 & 180 & 560 & $7,41-24,49$ & $-0,50-0,58$ & $0,00-0,77$ \\
\hline & & Degraus & 3,90 & 74 & 262 & 65 & 250 & $7,79-25,59$ & $-0,62-0,76$ & $0,00-0,98$ \\
\hline & & $\begin{array}{l}\text { Domínio } \\
\text { Serrano }\end{array}$ & 28,12 & 265 & 1645 & 255 & 1611 & $12,5-32,84$ & $-0,65-0,74$ & $0,00-0,99$ \\
\hline
\end{tabular}

\section{Considerações Finais}

O mapeamento geomorfológico da BHSJ utilizando análise de imagem orientada a objeto (OBIA) e mineração de dados permitiu, de forma ágil e simplificada, a classificação do relevo em diversas classes, em diferentes níveis taxonômicos e utilizando vários parâmetros de classificação.

A comparação com mapas geomorfológicos disponíveis para a área de estudo (DANTAS, 2001; SILVA, 2002; SEABRA, 2012) mostrou que as diferentes 
abordagens metodológicas adotadas para a confecção desses mapas foram capazes de diferenciar as grandes feições do relevo. Contudo, a metodologia adotada no presente estudo levou em consideração uma gama maior de parâmetros para a classificação geomorfológica em comparação aos trabalhos de Silva (2002) e Seabra (2012). Em relação ao mapa de Dantas (2001), a grande diferença foi a aplicação da OBIA e mineração de dados, que agilizou o trabalho e estabeleceu limiares mais bem definidos entre as classes mapeadas.

Ficou evidente que dois fatores influenciaram fortemente os resultados obtidos a partir da metodologia utilizada: (i) a segmentação; e (ii) a seleção do conjunto amostral. Destaca-se a grande dependência entre os resultados e a qualidade da segmentação. A segmentação multirresolução, com a possibilidade de se manipular a contribuição de cada variável, permitiu a elaboração de estratégias de segmentação mais adequadas aos dados utilizados e às classes geomorfológicas mapeadas. Esse é um importante aspecto, pois cada classe possui parâmetros de configurações ideais para o delineamento das suas subclasses.

A seleção do conjunto amostral é outro fator que teve grande influência nos resultados, pois possui uma relação direta na capacidade de classificação de forma correta das árvores de decisão geradas. Desse modo, essa etapa exige uma interferência direta por parte do especialista, a fim de selecionar amostras que não considerem padrões particulares e que representem somente os padrões mais genéricos.

A etapa de mineração de dados foi imprescindível para a agilidade da metodologia utilizada no presente estudo. A partir da mesma, foram obtidos, de maneira rápida, limiares de diferenciação entre classes, diminuindo consideravelmente o tempo gasto na seleção de atributos para essa diferenciação.

A classificação por meio da análise de imagem orientada a objeto se mostrou eficaz para o mapeamento geomorfológico, destacando-se dos métodos convencionais devido a sua capacidade de classificação em diferentes níveis e sua rede hierárquica semântica, onde cada classe pode ser dividida em subclasses, adequando-se bem ao mapeamento geomorfológico taxonômico proposto. É relevante destacar que foi necessária somente a correção de poucos erros de classificação por meio de edição manual, sendo que tais edições foram simples e rápidas.
Para estudos futuros é importante avançar na comprovação de tal método para o mapeamento geomorfológico de detalhe, investindo na utilização de MDE de alta resolução espacial, capazes de identificar pequenas feições no terreno. A inserção de dados qualitativos para o mapeamento geomorfológico por meio da metodologia adotada no presente estudo é outro ponto a ser melhor investigado, apesar de o procedimento utilizado ter apresentado bons resultados com a utilização de dados geológicos na classificação dos Maciços Alcalinos Intrusivos.

Por fim, vale destacar que, apesar do avanço no mapeamento por meio da OBIA e da mineração de dados, o conhecimento do especialista sobre o conteúdo a ser mapeado continua a ser imprescindível, pois é por meio desse conhecimento que é possível elaborar chaves de interpretação adequadas, sendo as mesmas fundamentais para o sucesso das demais etapas da metodologia adotada.

\section{Referências Bibliográficas}

ANDERS, N. S.; SEIJMONSBERGEN, A. C.; BOUTTEN, W. Segmentation optimization and stratified object-based analysis for semi-automated geomorphological mapping. Remote Sensing of Environment, v. 115, n. 12, p. 2976-2985, 2011.

ASSELEN, S.; SEIJMONSBERGEN, A. C. Expert-driven semi-automated geomorphological mapping for a mountainous area using a laser DTM. Geomorphology, v. 78, n. 3.4, p. 309320, 2006.

BAATZ, M.; SCHAPE, A. Multiresolution segmentation an optimization approach for high quality multi-scale image segmentation In: Strobl, J., Blaschke, T. (eds.). Angewandte Geographische Informationsverarbeitung XII. Beiträge zum AGIT Symposium Salzburg 2000. Karlsruhe: Herbert Wichmann Verlag, 2000. p. 12-23.

BENZ, U. C.; HOFMANN, P.; WIKKHAUCK, G.; LINGENFELDER, I.; HEYNEN, M. Multiresolution, objectoriented fuzzy analysis of remote sensing data for GIS-ready information. Photogrammetry \& Remote Sensing, v. 58, p. 239-258, 2004.

BISHOP, M. P.; JAMES, L. A.; SHRODER, JR; J. F.; WALSH, S. J. Geospatial technologies and digital geomorphological mapping: Concepts, issues and research. Geomorphology, v. 137, n. 1, p. 5-26, 2012.

CAMARGO, F. F.; FLORENZANO, T. G.; ALMEIDA, C. M.; 
OLIVEIRA, C. G. Abordagens cognitivas para a identificação de unidades geomorfológicas por meio de dados ASTER/ Terra. Revista Brasileira de Geociências, v. 39, n. 2, p. 276-288, 2009.

CORREIA, J. D. Metodologia para Mapeamento SemiAutomático de Feições Deposicionais Quaternárias por Imagens Orbitais de Alta Resolução Espacial: Médio Vale do Rio Paraíba do Sul. Tese (Doutorado em Geologia). 2008. Departamento de Geologia - IGEO/UFRJ, Rio de Janeiro, 2008.

DANTAS, M. E. Geomorfologia do Estado do Rio de Janeiro. In: CPRM - Serviço Geológico do Brasil. Projeto Rio de Janeiro. Brasília: CPRM. 2001.

DRAGUT, L.; BLASCHKE, T. Automated classification of landform elements using object-based image analysis. Geomorphology, v. 81, n. 3-4, p. 330-344, 2006.

DIAS, F. F. Variações do Nível Relativo do Mar na Região de Cabo Frio e Armação de Búzios - RJ: Reconstrução Paleoambiental e Cenários Futuros. 2009. Tese (Doutorado em Geologia). Departamento de Geologia - IGEO/UFRJ, Rio de Janeiro, 2009.

DRAGUT, L.; EISANK, C. Automated object-based classification of topography from SRTM data. Geomorphology, v. 141-142, n. 1, p. 21-33, 2012.

ESRI, 2014. ArcGIS 10.2 Desktop Help.

FERNANDES, P. J. F. Dados SRTM e derivados no mapeamento geomorfológico regional. 2013. 117 p. Dissertação (Mestrado em Sensoriamento Remoto) - Instituto Nacional de Pesquisas Espaciais (INPE), São José dos Campos, 2013.

NAVULUR, K. Multispectral image analysis using the objectoriented paradigm. Boca Raton, FL: Taylor \& Francis Group, 2007. 206p.

POÇANO, W.L.; CARNEIRO, C.D.R.; ALMEIDA, M.A.; PIRES NETO, A.G.; ALMEIDA, F.F.M. O conceito de sistemas de relevo aplicado ao mapeamento geomorfológico do estado de São Paulo. In: SIMPÓSIO DE GEOLOGIA REGIONAL, 2, 1979, Rio Claro, Anais... Rio Claro: SBG/NSP, 2013. p. 253-262.

QUINLAN, R. C4.5: programs for machine learning. San Francisco: Morgan Kaufmann, 1993. 316 p.

ROSS, J.L.S. Relevo brasileiro: uma nova proposta de classificação. Revista do Departamento de Geografia, n. 4, p. 25-38, 1985.

VALERIANO, M. M. Topodata: guia para utilização de dados geomorfológicos locais. São José dos Campos: INPE, 2008. 72 p.

VERHAGEN, P.; DRAGUT, L. Object-based landform delineation and classification from DEMs for achaeological predictive mapping. Journal of Archaelogical Science, v. 39, n. 3, p. 608-703, 2012.

SEABRA, V. S. Análise da paisagem em apoio aos estudos de favorabilidade à recuperação florestal da bacia hidrográfica do rio São João. 2012. Dissertação (Mestrado em Geografia). Instituto de Geociências, Universidade Federal do Rio de Janeiro, Rio de Janeiro, 2012.

SILVA, L.C.; CUNHA, H.C. Geologia do Estado do Rio de Janeiro. In: CPRM - Serviço Geológico do Brasil. Projeto Rio de Janeiro. Brasília: CPRM. 2001.

SILVA, T. M. A Estruturação geomorfológica do Planalto Atlântico no Estado do Rio de Janeiro. 2002. 265 p. Tese (Doutorado em Geografia) - Universidade Federal do Rio de Janeiro (UFRJ), Rio de Janeiro, 2002.

VIEIRA, M. A. Análise de imagem orientada a objeto e mineração de dados aplicadas ao mapeamento da cultura da cana-de-açúcar. 2010. 110 p. Dissertação (Mestrado em Sensoriamento Remoto) - Instituto Nacional dePesquisas Espaciais, São José dos Campos, 2010.

WITTEN. H.; FRANK, E.; HALL, M. A. Data mining practical machine learning tools and techniques. Morgan Kaufmann Publishers: Burlington. 2011. 629 p. 